University at Buffalo School of Law

Digital Commons @ University at Buffalo School of Law

\title{
The Altruistic Rich? Inequality and Other-Regarding Preferences for Redistribution
}

\author{
Matthew Dimick \\ University at Buffalo School of Law \\ David Rueda \\ Daniel Stegmueller
}

Follow this and additional works at: https://digitalcommons.law.buffalo.edu/journal_articles

Part of the Economics Commons, and the Law and Economics Commons

\section{Recommended Citation}

Matthew Dimick, David Rueda \& Daniel Stegmueller, The Altruistic Rich? Inequality and Other-Regarding Preferences for Redistribution, 11 Q.J. Pol. Sci. 385 (2017).

Available at: https://digitalcommons.law.buffalo.edu/journal_articles/975

The final publication is available from now publishers via 10.1561/100.00015099.

C) ${ }_{\text {COPYRIGHT }}^{\text {N }}$

This Article is brought to you for free and open access by the Faculty Scholarship at Digital Commons @ University at Buffalo School of Law. It has been accepted for inclusion in Journal Articles by an authorized administrator of Digital Commons @ University at Buffalo School of Law. For more information, please contact lawscholar@buffalo.edu. 


\title{
The Altruistic Rich? INEQUALITy AND OTHER-REGARDING PREFERENCES FOR REDISTRIBUTION
}

\author{
Matthew Dimick* \\ David Rueda $^{\dagger}$ \\ Daniel Stegmueller
}

First draft: 23 Jul 2014

This version: 12 Apr 2015

\begin{abstract}
What determines support among individuals for redistributive policies? Do individuals care about others when they assess the consequences of redistribution? Using data for the US from 1978 to 2010, we find that differences in redistribution preferences between the rich and the poor are high in some states and low in others. This difference has a lot to do with the rich and very little to do with the poor. While support for redistribution decreases with income, the preferences of the rich are very sensitive to the level of macro-inequality, and the rich are more supportive of redistribution in unequal states than they are in more equal states. To explain this relationship, we propose a model of other-regarding preferences for redistribution, which we term "income-dependent altruism." In making these distinctions between the poor and the rich, the arguments in this paper challenge some influential approaches to the politics of inequality.
\end{abstract}

\footnotetext{
*SUNY Buffalo Law School, mdimick@buffalo.edu

†University of Oxford and Nuffield College, david.rueda@politics.ox.ac .uk

tUniversity of Mannheim, mail@daniel-stegmueller.com
} 


\section{INTRODUCTION}

What determines support for government tax-and-transfer policies that redistribute income and reduce inequality? In the standard approaches to addressing this question, political economy models portray individuals as self-interested: they care only about how redistribution affects thier material welfare. Yet widespread dissatisfaction exists with this self-interested approach to preferences. Surely, the argument goes, individuals do not always make choices based only on such narrow concerns.

If we were to look at the preferences of rich and poor in different states in the US, as we do below, we would observe levels of support for redistribution among the rich that cannot be explained by material self-interest alone. Moreover, we would also observe very significant differences in how apart the rich are from the poor regarding their favored levels of redistribution. These important differences in support for redistribution have received little attention in the existing scholarship and yet they should be a most significant element in our explanation of outcomes as diverse (and as important) as the generosity of the welfare state, political polarization, varieties of capitalism, etc.

In this paper, we present a novel theory of redistribution preferences, termed "income-dependent altruism." In our model, individuals weigh the welfare of others as well as their own. Using American survey data, we present a set of empirical tests that support our hypotheses (and provide limited evidence in favor of alternative explanations). We find that after accounting for material self-interest, there is still a great degree of variation in redistribution preferences. Interestingly, we show that this variation has more to do with the preferences of the rich than those of the poor, and that it can be explained by taking into account the relationship between macro-inequality and altruism.

The argument explaining this variation can be summarized very simply. Because individuals care about their own welfare, the (relatively) poor support redistribution more than the (relatively) rich, as in the familiar self-interest approach. We could call this the relative income effect. However, because individuals are also other-regarding, there are two additional implications of our theory concerning what we could call the macro-inequality effect. Each of these implications depends on the simple notion that people have a diminishing marginal utility for consumption, that is, that a richer person values an additional dollar of consumption less than a poorer person. The 
first implication is that an increase in macro-inequality will lead to more support for redistribution from all individuals. While an increase in inequality reduces social welfare (because the rich value an additional dollar less than the poor), an increase in redistribution increases social welfare (for the same reason). Therefore, because individuals are altruistic - meaning that they are concerned about social welfare-they will support more redistribution in response to increasing inequality. The second and less obvious implication is that an increase in macro-inequality will lead to a larger increase in support for redistribution from the rich than from the poor. In this case, because the rich value an additional dollar less than the poor, an increase in redistribution aimed at reducing inequality is less costly (in welfare terms) to a richer person than to a poorer person (hence, our income-dependent altruism).

Theoretically, the contribution in this paper is to derive implications for preferences for redistribution from a social-welfare model of altruism (which, as far as we are aware, has not been done before). These implications are quite distinct and therefore challenge some influential approaches to the politics of inequality. These include other versions of the nature of other-regarding preferences (like the "inequity aversion" preferences proposed by Fehr and Schmidt 1999 or the "fairness" preferences analyzed by Alesina and Angeletos 2005) and those emphasizing insurance concerns (see, for example, Alt and Iversen 2013). We will elaborate on our differences from these approaches in the pages that follow, but we should clarify first how we approach the topic of other-regarding preferences.

The possibility that other-regarding concerns influence redistribution preferences has received increasing amounts of attention in the recent political economy literature. There is neural evidence that individuals have a dislike for unequal distributions, independent from social image or potential reciprocity motivations. Tricomi et al. (2010) use functional magnetic resonance imaging to test directly for the presence of inequality-averse social preferences in the human brain. In laboratory experiments, individuals have been shown to have concerns for the welfare of others (see, for example, Charness and Rabin 2002, and Fehr and Gächter 2000). A number of alternative models have been presented to analyze different kinds of other-regarding concerns (for reviews, see Fehr and Schmidt 2006 and DellaVigna 2009). As we have mentioned (and will document below), support for redistribution is widespread in the US and extends into income groups whose support for redistribution could not be 
motivated by short-term income maximization. Altruism constitutes one plausible reason why affluent individuals might support redistribution even though its effect is to reduce their disposable income and their share of total income. But "altruism is not an unpredictable 'social noise' to be randomly sprinkled over individuals" (Alesina and Giuliano 2011: 94). Altruistic concerns need to be systematized into predictable hypotheses. We follow Alesina and Giuliano (2011: 94) in arguing that "standard neoclassical general equilibrium theory can accommodate altruism, i.e., a situation in which one agent cares also about the utility of somebody else."

In this paper, we define altruism as concern about the welfare of others (e.g., Charness and Rabin 2002). This conception of altruism should be distinguished from those that construe altruism as a "taste for giving" (Andreoni 1989, 1990) or as a direct aversion to differences in material payoffs, as in Fehr and Schmidt (1999). There is also a significant literature on altruism as a personality trait. ${ }^{4}$ In this research altruism has often taken the form of a self-reported measure (the Self-Report Altruism, SRA, Scale) aggregating different items capturing an individual's engagement in altruistic behaviors (pushing a stranger's car out of the snow, giving money to a charity, etc).

In general then, one can contrast two approaches: The first analyzes altruism as an individual characteristic (personality trait, taste for giving) while the second understands other-regarding concerns to be affected by a "situational" logic (social welfare, inequity aversion). In this second category, other-regarding preferences are inevitably linked to macro levels of inequality. When altruism is significant, as the allocation of material payoffs become more equitable, the utility of individuals increases (see, for example, Fehr and Gächter 2000).

While we accept that the role of altruism as an individual characteristic in determining redistribution preferences is an important one, we emphasize a situational approach in this paper. We will show that it is very useful to argue that individual preferences for redistribution are affected by social welfare. We agree that, for many economic outcomes, personality measures are as predictive as cognitive ones (see, for example, Almlund et al. 2011) but find this compatible with our main argument. It is certainly possible that there are some individuals that have more altruistic personalities than others. But, as we will show in the next section, this would not affect the

\footnotetext{
${ }^{4}$ See, for example, the research on altruistic personality by Rushton et al. (1981).
} 
general implications of our argument about the relationship between redistribution preferences and macro levels of inequality.

It is important to finally emphasize in this introduction that this paper focuses on the demand for redistribution, and brackets away how (or even if) this demand is translated into policy. Inequality and redistribution in America have received, and for good reason, a resurgence in academic interest in recents times. Bartels (2009) has shown the spectacular increase in inequality over the past 35 years to be the product of policy choices in a political system dominated by partisanship and particularly receptive to the preferences of the wealthy. Hacker and Pierson (2011) coincide not only in the appreciation of the attention that policy-makers pay to the rich (and not the poor) in America, but also about the fact that politics is the main factor behind inequality ("American politics did it"). But we still know too little about the determinants of redistributive preferences. ${ }^{5}$ In fact, we agree with McCarty et al. when they argue that:

"Although much recent work in comparative political economy has sought to link inequality to political conflict and back to economic policy, few of these insights have been applied to American politics." (McCarty et al. 2008: 73).

If inequality matters to individual political behavior, however, it seems reasonable to assume that it does so through its influence on redistribution preferences. Analyzing the demand for redistribution is therefore an essential first step for an accurate understanding of the supply of redistribution and it is this task that this paper now turns to.

\section{A MODEL OF ALTRUISTIC PREFERENCES FOR REDISTRIBUTION}

This section introduces our proposed model for understanding the relationship between self-interest, other-regarding concerns, and preferences for redistribution, which we call income-dependent altruism. We then demonstrate the distinctiveness of our results by contrasting our model with several prominent alternatives.

\footnotetext{
${ }^{5}$ Paradoxically, this is a topic that has been the focus of more research in the economics (see, for example, Alesina and La Ferrara 2005, Fong 2001, and Keely and Tan 2008) than in the political science literature.
} 


\section{Income, Redistribution, and Budgets}

Let there be a set of $n$ individuals, indexed by $i, i \in\{1,2, \ldots, n\}$. Individuals are distinguished by their gross income level, $y$. Thus, the gross income of the $i$ th individual is given by $y_{i}$, where $0 \leq y_{i}<y_{j} \leq \infty$ for $i<j$. Average income is then defined as

$$
\bar{y}=\frac{1}{n} \sum_{i=1}^{n} y_{i}
$$

The government operates a linear tax, $\tau, \tau \in[0,1]$, and distributes the proceeds to all citizens in equal lump-sum transfers, $T$. The size of the transfer is determined by government revenue, $\tau \bar{y}$, less the costs of taxation $\phi(\tau) \bar{y}$. To keep the model as simple as possible, we assume that $\phi(\tau)=\frac{1}{2} \tau^{2}$. The government's budget is balanced, so

$$
T=\left(\tau-\frac{1}{2} \tau^{2}\right) \bar{y}
$$

With taxes and transfers, each agent's budget constraint, equivalent to her consumption or disposable income, is then given by:

$$
c_{i}=(1-\tau) y_{i}+T
$$

\section{Preferences}

Individuals have a separable utility function consisting of both their own utility (or self-interested utility), $u\left(c_{i}\right)$, which is defined over each person's disposable income $c_{i}$, and other-regarding utility, $\Omega$, parameterized by $\delta$ :

$$
V\left[u\left(c_{i}\right), \Omega\right]=(1-\delta) u\left(c_{i}\right)+\delta \Omega
$$

In this set-up, $\delta \in(0,1)$ determines how much weight an individual places on individual versus social welfare: a larger $\delta$ means the person cares more about social welfare and less about individual welfare. It would be perfectly plausible to allow the parameter $\delta$ to vary across different individual types - altruistic versus non-altruisticin which case we would write $\delta_{i}$. However, not allowing $\delta$ to vary makes clear that our results, in particular the relationship between income and inequality, do not depend on such variation. 
For the agent's own utility, we impose the following standard restrictions on $u$ :

$$
\begin{aligned}
& u^{\prime}(c)>0, \\
& u^{\prime \prime}(c)<0, \text { and } \\
& \lim _{c \rightarrow 0} u^{\prime}(c)=\infty,
\end{aligned}
$$

In addition, in certain cases it will be either convenient or necessary to adopt a specific form for these assumptions:

$$
u(c)=\frac{c^{1-\epsilon}}{1-\epsilon}, \text { for } \epsilon \in(0,1)
$$

One implication of this specification is that $u$ exhibits the Arrow-Pratt measure of constant relative risk aversion (CRRA; Pratt 1964): $R(c)=-c u^{\prime \prime}(c) / u^{\prime}(c)=\epsilon$. Note our assumption on $\epsilon$, which will imply, following Iversen and Soskice (2001) and Moene and Wallerstein (2001), that the amount of redistribution preferred by an individual will decrease as her income increases.

As for other-regarding preferences, we assume that they take the form of a standard social welfare function:

$$
\Omega=\frac{1}{n} \sum_{j=1}^{n} u\left(c_{j}\right)
$$

which is simply the average of all individuals' utility. We explicate and explore the implications of these assumptions in the following section.

\section{MODEL RESULTS}

\section{A. Implications of the Model}

A critical implication of the social welfare function is that it directly reflects levels of income inequality, which is made explicit by the following lemma. The basis behind this identity is straightforward. It was demonstrated in a classic paper by Atkinson (1970), which constructs an index of inequality from a standard social welfare function. Assuming the specification for constant relative risk aversion in equation (6), we denote this Atkinson Index as $Q \in[0,1]$, with 0 implying perfect income equality (everyone has equal income) and 1 perfect inequality (one person 
owns all income). The index is given by:

$$
Q\left(\tau ; c_{1}, c_{2}, \ldots, c_{n}\right)=1-\frac{1}{\bar{c}}\left(\frac{1}{n} \sum_{i=1}^{n} c_{i}^{1-\epsilon}\right)^{1 /(1-\epsilon)}, \text { for } \epsilon \in(0,1)
$$

where $\bar{c}$ denotes average disposable income. The identity between the social welfare function and inequality is stated formally in the following lemma.

Lemma 1. (Social welfare and inequality.) The social welfare function can be expressed in terms of both mean income, $\bar{c}$, and inequality, $Q$, as defined by the Atkinson Index:

$$
\Omega=u[\bar{c}(1-Q)]=u\left(c_{e}\right)
$$

where $\bar{c}(1-Q)$ is the abbreviated social welfare function and $c_{e}$ is described as equally distributed equivalent income.

Proof. See Appendix A.

Hence, the expression $\bar{c}(1-Q)$ captures the idea that as inequality increases social welfare decreases. Slightly more formally, a larger $Q$ (higher inequality) implies a smaller $\bar{c}(1-Q)$, which is equivalent to a reduction in $\Omega$ (lower social welfare). As stated, the fact that the social welfare function can be expressed directly in terms of inequality shows that the social welfare function is also a measure of inequality. The lemma has two additional implications. First, it dictates the choice of the measure of inequality we use in our empirical analysis, which is the Atkinson Index. In addition, the identity with the utility of equally distributed equivalent income serves a more technical purpose, which is explained in the proof to the lemma.

Most importantly for our argument, the relationship between the social welfare function and income inequality means that, although social welfare is simply an aggregate of all individuals' utility, the social welfare function also affects inequality aversion. This is because utility functions are concave-that is, individuals have diminishing marginal utility of consumption. Consequently, because the rich value an additional dollar of consumption less than the poor, transferring a dollar from the poor to the rich-that is, increasing the level of inequality-reduces social welfare. By the same token, transferring a dollar from the rich to the poor increases social welfare. 
Before proceeding, we pause to acknowledge that whose social welfare or which inequality is considered by an individual is an open theoretical question. We can think of compelling reasons for why individuals would be concerned about national level inequality (if redistribution occurs primarily through national institutions), regional/state and local levels of inequality (if salience, proximity, or availability of information matters to altruism), or all of them together. To anticipate our empirical analysis, we attempt to fully exploit the available data by construing the social-welfare function as being composed of state-level incomes and utility functions, even though self-interested preferences (as well as the administration of tax and transfer programs) are oriented toward the national level. This decision changes none of the theoretical insights we describe below.

Turning to the implications of our conception of altruism for individual preferences for redistribution, we advance four distinct claims. Our first and most straightforward claim is that the level of redistribution preferred by an individual is decreasing in her income, which would also be the case if individuals were purely self-interested . This is because although individuals have mixed motives (they care about inequality and social welfare), they still care about the impact that redistributive policies have on their own welfare. Accordingly, richer individuals support less redistribution than poorer individuals.

Second, there is some income threshold above which an individual prefers no redistribution and below which an individual prefers some positive amount of redistribution. This threshold also exists in the standard, self-interested model of redistributive preferences. However, the critical difference in our model is that this threshold is strictly above the income threshold that would obtain with purely self-interested individuals. This result follows directly from our altruistic model of preferences. Because individuals care about the welfare of others, relatively affluent individuals are willing to support more redistribution than they would if they were merely self-interested.

Third, an increase in inequality will increase an individual's demand for redistribution. This result follows from the effect of an increase in inequality on social welfare and individuals' other-regarding preferences. Because inequality decreases social welfare, it also lowers individuals' utility, via their other-regarding concerns. Thus, by increasing redistribution, individuals can reduce inequality and increase social welfare. 
The final claim that we make is the most important statement we derive from our model of altruistic preferences for redistribution. Even though the rich prefer less redistribution than the poor, we claim that an increase in inequality will lead to a larger increase in support for redistribution from the rich than from the poor. Although perhaps counterintuitive at first, this claim can be simply understood within our basic conception of altruistic preferences. As we have seen, the assumption of a concave utility function plays a crucial role in shaping inequality aversion with respect to the other-regarding portion of an individual's preferences. But it also plays an important role in individuals' own self-interested preferences for consumption over redistribution. A rich person prefers less redistribution than a poor person for self-interested reasons, but an increase in inequality increases her demand for redistribution more than a poor person. This is because she values an additional dollar of consumption less than a poor person does. She would therefore rather spend more of that dollar on redistribution than on personal consumption. In contrast, when inequality increases, a poor person, who already favors more redistribution for self-interested reasons, values an additional dollar of consumption more and would rather spend more of that dollar on personal consumption than on alleviating inequality. Thus, at the margin, a richer individual is willing to trade more consumption for redistribution even though overall she prefers less redistribution than a poor person.

We also demonstrate that this final result obtains only if there is diminishing marginal utility of consumption. Thus, one might argue that increases in inequality do not change the preferences of the poor very much because they already favor a higher amount of redistribution. And indeed such an effect can be identified in the model. However, this effect is not sufficient by itself to explain the positive interaction between income and an increase in inequality. If utility functions are not concave, this interaction effect is zero.

These results can be summarized in the following proposition:

Proposition 1. (Income-dependent altruism.) The model of altruistic preferences given by equation (4) has the following properties:

(A) For $y_{i} \geq \hat{y}$, the level of redistribution preferred by individual $i$, denoted $\tau_{i}^{*}$, is $\tau_{i}^{*}=0$. For $y_{i}<\hat{y}$, the preferred level of redistribution satisfies $0<\tau_{i}^{*}<1$. Furthermore, we note that $\hat{y}>\bar{y}$ : the income threshold for preferring some positive amount of redistribution is greater than mean income. 


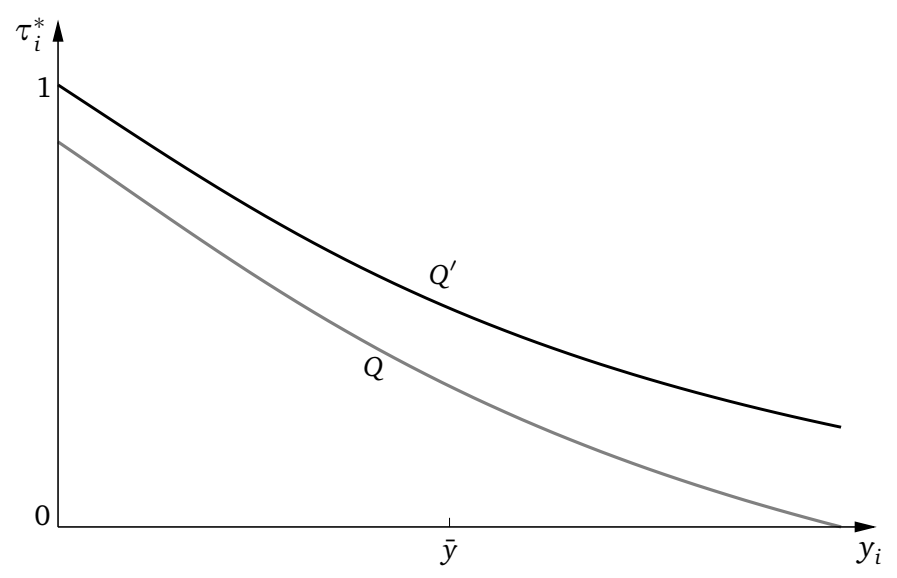

Figure 1: Income-dependent altruism: The effect of an increase in inequality (from $Q$ to $Q^{\prime}$ ) on redistribution preferences

(B) An individual i's preferred level of redistribution $\tau_{i}^{*}$ is decreasing in individual income $y_{i}$. Formally, $\frac{\partial \tau_{i}^{*}}{\partial y_{i}}<0$ for all $y_{i} \in[0, \hat{y}]$.

(C) An individual $i$ 's preferred level of redistribution $\tau_{i}^{*}$ is increasing in inequality $Q$. Formally, $\frac{\partial \tau_{i}^{*}}{\partial Q}>0$ for all $y_{e} \in[0, \bar{y}]$.

(D) The effect of an increase of inequality $Q$ on an individual i's preferred level of redistribution $\tau_{i}^{*}$ is increasing in individual income $y_{i}$. Formally, $\frac{\partial^{2} \tau_{i}^{*}}{\partial Q \partial y_{i}} \geq 0$ for all $y_{i} \in[0, \hat{y}]$. Furthermore, this is true if and only if the utility function is strictly concave. That is, for all $\epsilon \in[0,1), \frac{\partial^{2} \tau_{i}^{*}}{\partial Q \partial y_{i}} \geq 0$ if and only if $\epsilon>0$; otherwise, $\frac{\partial^{2} \tau_{i}^{*}}{\partial Q \partial y_{i}}=0$.

Proof. See Appendix A.

Figure 1 graphically depicts the impact of an increase in inequality on redistributive preferences. ${ }^{6}$ With income displayed on the horizontal line and redistributive preferences on the vertical line, the two curves represent the relationship between an individual's income and her redistribution preferences at two different levels of inequality. The lower line represents a lower level of inequality $(Q)$, while the upper curve corresponds with a higher level of inequality $\left(Q^{\prime}\right)$. Thus increases in inequality

\footnotetext{
${ }^{6}$ To plot these utility functions we set $\epsilon$ and $\delta$ to 0.5 .
} 
shift the income-redistribution curve upwards. As explained in the previous paragraphs, this implies that an increase in inequality increases demand for redistribution from all individuals, regardless of income. However, as theorized above, note that the distance between the two curves increases as one moves up the income scale. Thus, an increase in inequality has a smaller effect on the redistributive preferences of the poor and a larger effect for the rich.

\section{B. Distinguishing the Model}

We are of course not the first to suggest that other-regarding concerns play a role in support for redistribution. In this section, we distinguish the implications of our model from alternative approaches. Because our argument highlights the other-regarding consequences of economic inequality, we focus on those models with similar features. ${ }^{7}$ The most influential ones in the political economy literature are Fehr and Schmidt's (1999) on "reference-dependent inequity aversion" and Alesina and Angeletos's (2005) on "fairness" preferences. The inequity-aversion preferences of Fehr and Schmidt have been widely cited and applied ${ }^{8}$ and are based on extensive experimental evidence. By distinguishing between "fair" and "unfair" inequalities, the argument by Alesina and Angeletos accords with the popular notion that only inequality in opportunities, rather than outcomes, deserves to be corrected. Furthermore, it has been generally received as a compelling resolution of the puzzling macro-comparative finding (the so-called "Robin Hood" paradox) that redistribution is higher when inequality is lower-i.e., where there appears to be less need for redistribution.

In Fehr and Schmidt's conception, inequality comes at a cost to individuals' otherregarding utility. But how an individual evaluates inequality depends on how her income relates to those of others. Differences in income between an individual and those with income greater than hers is termed "disadvantageous inequality" or envy. Differences in income between an individual and those with income less than hers is called "advantageous inequality" or altruism. The critical restriction that Fehr and Schmidt place on their version of other-regarding preferences is that

\footnotetext{
${ }^{7}$ Thus, we do not directly address "social distance" models (e.g., Lupu and Pontusson 2011; Shayo 2009), which highlight the limits of other-regardingness, or models such as "last-place aversion" preferences (Kuziemko et al. 2014), which make predictions about the effects of inequality on only a smaller subset of the population.

${ }^{8}$ For a recent application in political science, see, e.g., Lü and Scheve (2014).
} 
concern about advantageous inequality is assumed to matter less than concern about disadvantageous inequality. Alternatively, one could say that individuals are assumed to be more envious than they are altruistic.

This assumption has important implications for redistributive preferences. Similar to altruistic preferences, the inclusion of other-regarding utility raises the income threshold of the person who favors the least, but some positive, amount of redistribution. Whether advantaged or disadvantaged by inequality, any amount of inequality comes at a cost to individuals' other-regarding utility. Thus, the existence of any amount of inequality increases an individual's demand for redistribution relative to her purely self-interested preferences. However, for Fehr and Schmidt, poorer individuals have a stronger reaction to changes in inequality than richer individuals (which is the opposite of the implication from our model). On the one hand, an increase in inequality comes at an other-regarding cost to all individuals. On the other, for those poor individuals lower down on the income scale, this change is more likely to increase their disadvantageous inequality, while for those rich individuals higher on the income scale, this will increase their advantageous inequality. Since envy is weighted more than altruism in Fehr and Schmidt's model, a rise in inequality will have a larger impact on the poor than on the rich and will increase the demand for redistribution more from the poor than from the rich.

The arguments in Alesina and Angeletos (2005) are based on the idea that individuals have both "earned" or "fair" income as well as "unearned" or "unfair" income, and that only "unfair" income comes at a utility cost to individuals. Thus, inequality of final outcomes is of little concern to individuals, and they may tolerate a high degree of it, provided that it is "fair." The first implication is that, provided there is at least some unearned inequality, the income level of the person who wants at least some amount of redistribution increases relative to the self-interested threshold, just as with altruism and inequity aversion.

However, different from both altruism and inequity aversion, under fairness preferences an increase in inequality lowers all individuals' demand for redistribution. This is because it is not always clear how much of an individual's income is a result of effort rather than luck. When inequality is high,differences in income are assumed to be driven primarily by differences in returns to talent, ability and effort. Conversely, when inequality is low, it is assumed to be the product of arbitrary luck, rather than 

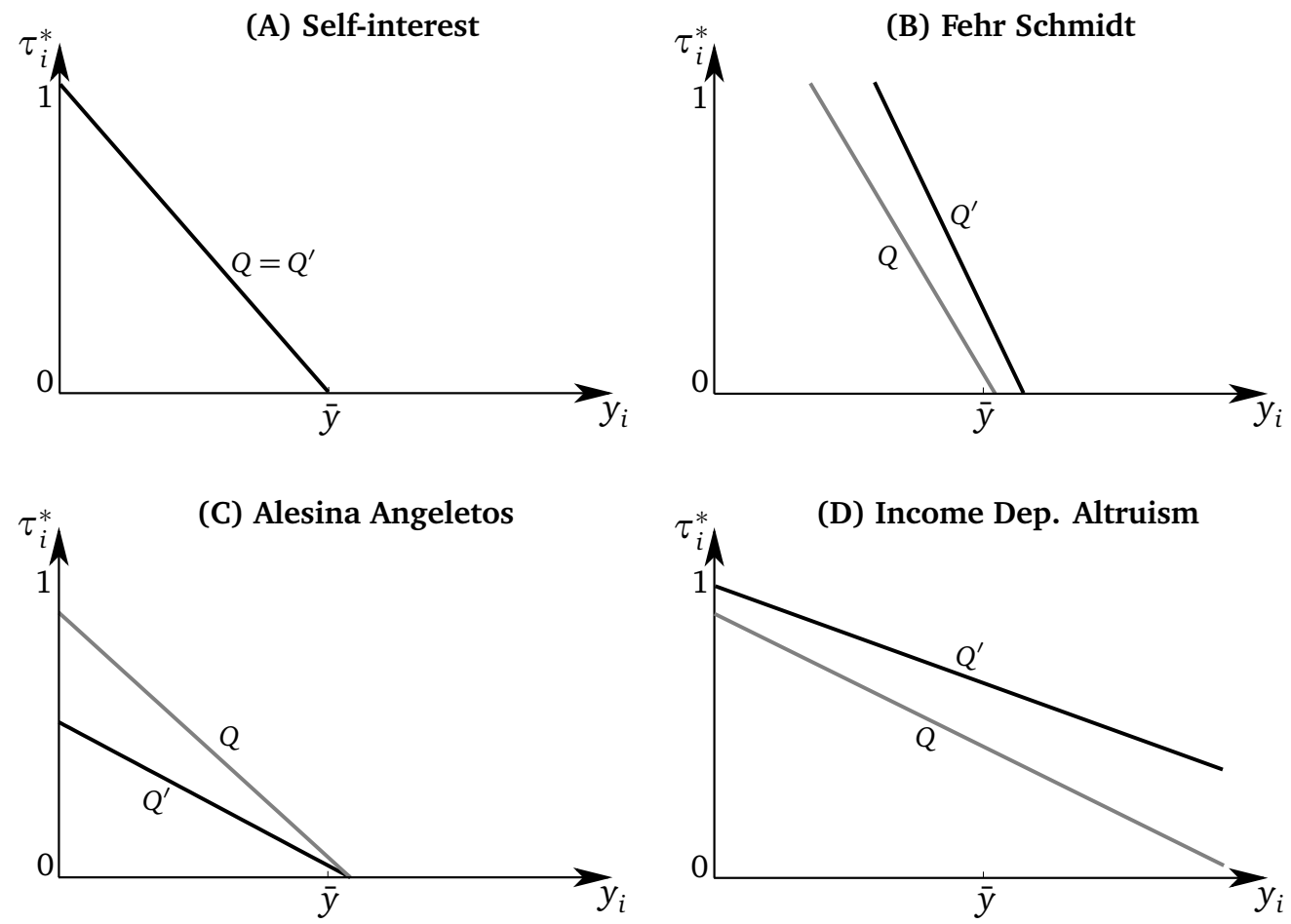

Figure 2: Implication of changes in inequality for redistribution preferences in four alternative models. Low $(Q)$ and high $\left(Q^{\prime}\right)$ inequality. Mean income is denoted by $\bar{y}$.

effort. Since individuals with fairness concerns want to correct for luck income rather than earned income, they will favor more redistribution when inequality is low than when it is high. Thus, an increase in inequality will lower an individual's preferred level of redistribution (the opposite implication from the one proposed in this paper).

Figure 2 illustrates four different models of preferences - pure self-interest (A), inequity aversion (B), fairness (C), and income-dependent altruism (D) - and the distinct patterns of income, inequality, and preferences for redistribution they imply. Getting similarities out of the way first, we can observe that in all other-regarding models (B to D) the level of redistribution preferred by an individual is decreasing in her income, just like in the classic Meltzer-Richard model. This reflects the fact that individuals have mixed motives: although agents may be other-regarding, they care for their own interests as well. Note also that in all of the other-regarding models, concern about inequality increases the income domain over which individuals prefer 
at least some positive amount of redistribution. When individuals are purely self interested, no one above the mean income prefers any level of redistribution. When individuals have other-regarding concerns, at least some with income above the mean prefer some redistribution. This is the result of other-regardingness in action: concern about others' welfare leads individuals to favor more redistribution than if they were purely self interested. ${ }^{9}$

Turning now to differences, the first observation to make is the way that a meanpreserving increase in inequality changes preferences for redistribution. Such a change has an effect in all of the other-regarding models, but not the self-interested one. A mean-preserving change in inequality makes no difference to self-interested persons with the same income under either distribution. For both inequity aversion (B) and income-dependent altruism (D), an increase in inequality increases the demand for redistribution for individuals of all income types. This is because both kinds of preferences exhibit inequality aversion: inequality in any form comes at a cost to other-regarding utility. In contrast, an increase in inequality lowers the demand for redistribution with fairness preferences (C). This is because fairness preferences are concerned only with unearned or unfair inequality, in contrast to earned or fair inequality. With fairness preferences, when inequality is high (low), differences in income are assumed to be less (more) likely the product of luck, and therefore there is less (more) of a desire to reduce actual inequality.

The second major observation is how an increase in inequality affects individuals at different points in the income scale. For inequity-aversion preferences, an increase in inequality increases the demand for redistribution, but this effect decreases as income increases. This is, as we have explained above, because individuals care more about what Fehr and Schmidt call disadvantageous inequality (or, envy) than about advantageous inequality (or, altruism).

In summary, the predictions of income-dependent altruism are quite different from those of inequity-aversion or fairness models. Unlike fairness preferences, but like inequity aversion, an increase in inequality increases the demand for redistribution.

\footnotetext{
${ }^{9}$ Note that in all cases mean income, $\bar{y}$, is not substantively important. Depending on parameters, this reference point could take on several possible values. The important observation to make is the difference that other-regarding concerns make to the threshold condition, $\hat{y}$, relative to self-interested preferences.
} 
And unlike both fairness and inequity-aversion preferences, the effect of an increase in inequality is larger for the rich than the poor. ${ }^{10}$

Before turning to the empirical tests of our hypotheses, it is necessary to contrast our model with another important approach to social-policy preferences, namely the "insurance model" (e.g. Iversen and Soskice 2001). Although not a model with other-regarding preferences, both the insurance model and the one presented in this paper have similar foundations. Indeed, it is a well-known economic result that the strict concavity of a utility function implies both risk aversion as well as inequality aversion (Mas-Colell et al. 1995: 826). Moreover, in a recent paper, Alt and Iversen (2013) argue that a model of altruism incorporating "social distance" and an insurance model with segmented labor markets yield substantively identical conclusions. Nevertheless, our model of income-dependent altruism retains some implications that are distinct from the social insurance model. This is mainly because in our altruism model inequality directly affects individuals' utility but also because it does not feature a social distance parameter. Consequently, while the thrust of the model analyzed by Alt and Iversen is that increases in inequality will reduce demand for redistributive social insurance, our argument is precisely the opposite, namely, that a rise in inequality will lead individuals to favor more redistribution.

\section{TESTING THE MODEL}

Our statistical specification closely follows our theoretical model. From the first order condition of individual $i$ 's utility function in (4) we derive the theoretical function $\tau_{i}^{*}\left(y_{i}, Q\right)$, which represents $i$ 's preferred level of redistribution, $\tau_{i}^{*}$, given $i$ 's income, $y_{i}$, and the level of inequality, $Q$. The (partial) second-order Taylor expansion of $\tau_{i}^{*}\left(y_{i}, Q\right)$ is given by: ${ }^{11}$

$$
\tau_{i}^{*}=x+\frac{\partial \tau_{i}^{*}}{\partial y_{i}} y_{i}+\frac{\partial \tau_{i}^{*}}{\partial Q} Q+\frac{\partial^{2} \tau_{i}^{*}}{\partial Q \partial y_{i}} Q y_{i}
$$

\footnotetext{
${ }^{10}$ The theoretical interactions between income and inequality in the models of Fehr and Schmidt and Alesina and Angeletos have not, to our knowledge, been derived in the literature. Proofs of these statements are available from the authors upon request.

${ }^{11}$ We simplify by ignoring the higher order quadratic terms (which are relegated to the remainder). We also estimate the full equation (including higher order terms) using nonlinear least squares and obtain the same core result. Details are available in Appendix B.
} 
so that our estimated regression equation is of the form

$$
R_{i}=b y_{i}+c Q+d Q y_{i}
$$

Here $R_{i}$ is an individual's measured level of redistribution preference, and $b, c$, and $d$ are estimated parameters representing part (B), (C), and (D) of proposition 1 . If our estimate of $b$ is significantly (in the statistical and substantive sense) smaller than zero, we can infer that $\frac{\partial \tau_{i}^{*}}{\partial y_{i}}<0$ and confirm part (B) of proposition 1 ; if our estimate of $c$ is significantly larger than zero, we infer that $\frac{\partial \tau_{i}^{*}}{\partial Q}>0$ confirming part (C). Finally, in testing our central hypothesis, if our estimate of $d$ is significantly larger than zero, we show that $\frac{\partial^{2} \tau_{i}^{*}}{\partial y_{i} \partial Q}>0$ and confirm part (D) of proposition 1 .

\section{A. Data}

We estimate our model using a panel of repeated individual level surveys. The General Social Survey (GSS) covers more than thirty years and contains measures for individual income and preferences. It therefore has figured prominently in studies of redistribution preferences (e.g., Alesina and Angeletos 2005; Alesina and Giuliano 2011). Our theoretical argument proposes that the importance of inequality emerges from its relationship to altruism. This implies that the relevant level of macro inequality should be one at which a visible connection to the need of the poor (and the moral benefits of generosity) could be made by individuals. We therefore move away from national data and use state levels of inequality matched to the GSS. We select surveys starting with 1978 (where redistribution preference measures become available) and ending in 2010. We limit our population to working-age (20-65) individuals who are not currently in full-time education. These restrictions yield 21,704 observations. After removing individuals with missing values on covariates, we are left with 19,025 individuals. $^{12}$

\section{B. Statistical specification}

Let $R_{\text {ist }}$ be the stated redistribution support of individual $i\left(i=1, \ldots, N_{s t}\right)$ in state $s(s=1, \ldots, S)$ at time $t(t=1, \ldots, T)$. Observed survey responses are distinct

\footnotetext{
${ }^{12}$ Multiple imputation does not yield substantively different results. Results available from the authors.
} 
from preferences. We thus use a latent variable setup, where observed responses are generated by an underlying continuous latent preference variable $R_{\text {ist }}^{*}$ (e.g., Greene 2002: 669). Since we are interested in the effect of changes in inequality, we opt for a specification which includes state-specific constants, $\xi_{s}$, as well as common time shocks, $\lambda_{t}$. Due to the nature of our repeated cross-section survey data, some states have fewer observations per time-point than others. To overcome this limitation, we specify a hierarchical model for state-specific effects, yielding shrinkage estimates for preferences (Jiang 2007; Rabe-Hesketh and Skrondal 2008). This leads us to estimate the following hierarchical probit specification:

$$
\begin{aligned}
& R_{i s t}=\mathbf{1}\left(R_{i s t}^{*}>0\right) \\
& R_{i s t}^{*}=\boldsymbol{\beta}^{\prime} \boldsymbol{x}_{i s t}+\gamma_{1} y_{i s t}+\gamma_{2} Q_{s t}+\gamma_{3} Q_{s t} y_{i s t}+\lambda_{t}+\xi_{s}+\epsilon_{i s t}
\end{aligned}
$$

The effect of our variables of interest is captured by the three $\gamma$ coefficients, which capture the role of income distance, $y_{i s t}$, the direct effect of inequality in state $s$ in year $t, Q_{s t}$, and the effect of inequality conditional on income, $Q_{s t} y_{i s t} \cdot{ }^{13}$ We include an intercept and a number of individual and state-level controls in $\boldsymbol{x}_{i s t}$, with associated effect estimates $\boldsymbol{\beta}$. Residuals $\epsilon$ are distributed normal with unit variance. ${ }^{14}$

As discussed above, our state-specific effects follow a hierarchical specification, i.e., we specify them as draws from a normal distribution centered at zero with variance $\psi^{2}$ estimated from the data,

$$
\xi_{s} \sim N\left(0, \psi^{2}\right), s=1, \ldots, S
$$

We estimate this model using restricted maximum likelihood and integrate over the random state effects distribution using adaptive Gaussian quadrature with 15 integration points (Rabe-Hesketh et al. 2005).

We investigate the robustness of our model choice in three ways. We estimate a specification where states are fixed effects, as well as a linear probability specification with state and time fixed effects (with $R_{i}$ instead of $R_{i}^{*}$ as the dependent variable).

\footnotetext{
${ }^{13}$ Thus, $\gamma_{1}$ corresponds to $b$ in eq. (11), $\gamma_{2}$ to $c$, and $\gamma_{3}$ to $d$.

${ }^{14} \mathrm{We}$ estimate a probit model since we create a binary redistribution support indicator (described below) which allows for easier presentation of results (in terms of the probability of supporting redistribution). But note that both a more complex hierarchical ordered probit model as well as a simpler linear probability model yield substantively identical results.
} 
Table 1: Distribution of redistribution preferences (in \%), 1978-2010

\begin{tabular}{|c|c|c|c|c|c|c|c|}
\hline \multicolumn{7}{|c|}{ 7-point response scale } & \multirow{3}{*}{$\begin{array}{l}\text { Support } \\
\text { Indicato }\end{array}$} \\
\hline No & & & & & & Yes & \\
\hline 1 & 2 & 3 & 4 & 5 & 6 & 7 & \\
\hline 12.7 & 7.9 & 13 & 19.2 & 18.2 & 10.6 & 18.3 & 28.9 \\
\hline
\end{tabular}

We also estimate the model in a Bayesian framework using nonparametric density estimation for state- and time-specific effects.

\section{Dependent and independent variables}

Preferences We capture redistribution preferences using a commonly used measure (e.g., Alesina and Angeletos 2005), available repeatedly in the GSS. It presents respondents with the following statement: "the government should reduce income differences between the rich and the poor, perhaps by raising the taxes of wealthy families or by giving income assistance to the poor". Answers are recorded on a seven point scale, with labeled endpoints " $1=$ should" and " $7=$ should not", which we reverse for ease of interpretation. Table 1 shows the distribution of responses in our sample. It is immediately apparent that preferences regarding redistribution are polarized: a relatively large number of responses are concentrated at both extremes of the scale. As many as $18 \%$ of the individuals in a survey clearly declare the government should reduce income differences, while as many as $13 \%$ vehemently declare that it should not. For our statistical model we create an indicator variable which is equal to one if a respondent indicates clear support of redistribution by choosing the highest or second highest answer category (displayed in the last column of Table 1). While the table provides a bird's eye view of Americans' redistribution preferences, we must keep in mind that these are aggregate numbers (and do not reflect the within-state and time variation to be emphasized below).

Inequality Our model conceptualizes inequality via the Atkinson index (see equation 8). We directly translate this into an empirical measure, by using state-level Atkinson indexes for each year, denoted $Q_{s t}$ (Atkinson 1970; Cowell 2000). The basis for our calculations is tax return data from the Internal Revenue Service. This is preferable 


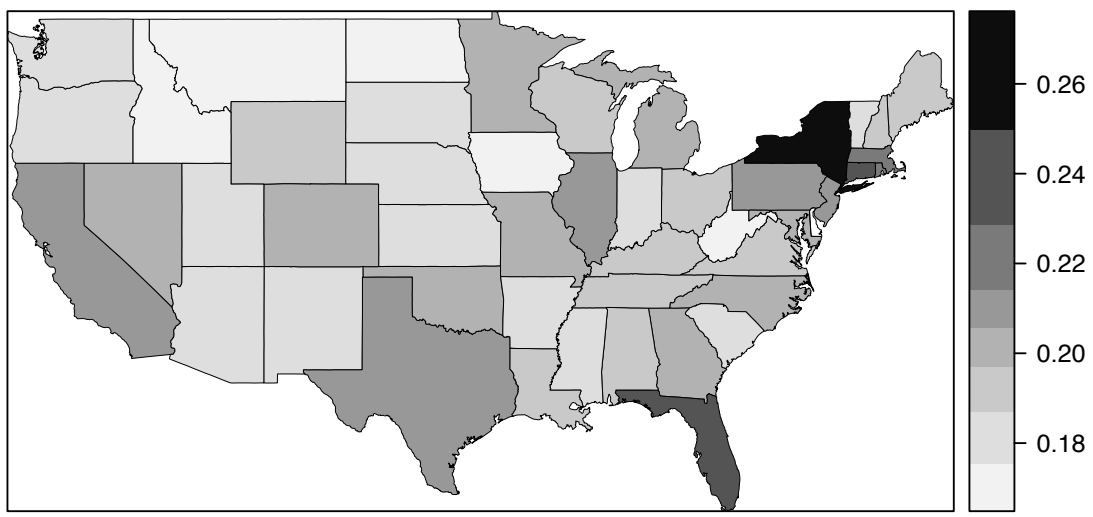

Figure 3: Map of inequality $\left(Q_{s t}\right)$ by state, $1978-2010$.

to survey-based calculations, as argued in detail by Atkinson et al. (2011). Not only are the very rich underrepresented in standard surveys but, in order to protect respondents' anonymity, incomes are usually top-coded. Consequently, the extent of inequality tends to be underestimated when calculated from sample surveys. Matters are improved when inequality is calculated from administrative records. We use the Atkinson index from Frank (2009) who calculates a number of inequality measures following Cowell and Mehta (1982) based on IRS data.

Figure 3 shows average levels of inequality by state over the period in our analysis. The figure shows inequality to be the highest in New York, Massachusetts, Connecticut, Florida, Texas and California. The most equal states are Nevada, Idaho, Indiana, West Virginia, and Washington. Since the analysis to be developed below will emphasize temporal within-state variation, Figure 4 shows the evolution of inequality in different states (and regions) in the US from 1970 onward. The figure illustrates a secular increase in inequality from 1970 to 2010, but it also shows the degree of these increases to be quite different in specific states. In the Northeast, for example, the levels of inequality across states are quite similar in 1970. By 2010, however, the Atkinson index had increased only from 0.17 to around 0.25 in some states, while it had experienced a much more explosive increase (from 0.17 to more than 0.35 ) in others. 


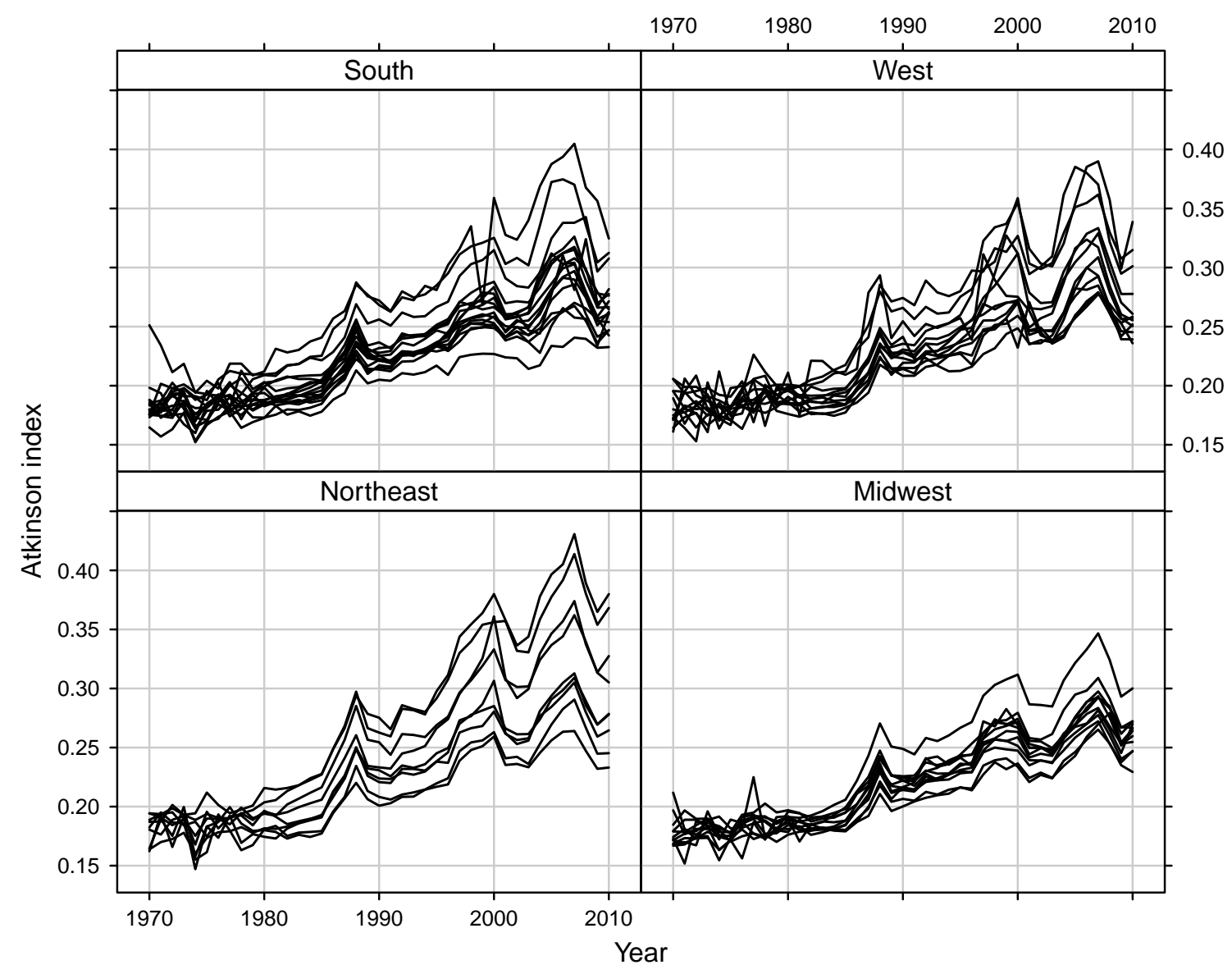

Figure 4: Evolution of inequality, $Q_{s t}, 1970-2010$

Our choice of inequality measure follows directly from our theoretical model. ${ }^{15}$ Furthermore, the Atkinson index has a number of desirable properties (such as subgroup decomposability; e.g., Shorrocks 1980). However, some researchers might be more familiar or comfortable with the Gini index as a measure of inequality. Therefore, we also provide results with inequality measured via the Gini coefficient, from the same source (Frank 2009), in our robustness section.

Income distance We measure income distance as the distance between a respondent's household income and average national income in each year. ${ }^{16}$ The GSS captures

\footnotetext{
${ }^{15}$ The sensitivity parameter $\epsilon$ of the estimated Atkinson index (which is general in our theoretical model) is set to 0.5 in (Frank 2009).

${ }^{16}$ This represents a simple centering, which leaves the distribution of incomes unchanged.
} 
income by asking respondents to place their total net household income into a number of income bands. Following standard practice in the American Politics literature, we transform income bands into midpoints (see e.g., Hout 2004). The top-coded income category value is imputed by assuming that the upper tail of the income distribution follows a Pareto distribution (e.g., Kopczuk et al. 2010). Finally, to allow meaningful comparison over time, incomes are converted to constant dollars (with base year 2000).

Controls To control for state-specific changes in economic conditions, we use yearly state-level unemployment rates. We calculate them by averaging the LA series from the Bureau of Labor Statistics for state monthly unemployment rates (Bureau of Labor Statistics 1992). As further individual-level controls we include a respondent's age, gender, education (years of schooling), an African-American indicator variable, and a "non-white" summary indicator. Respondents' labor market status is captured by indicator variables for currently being self-employed, unemployed, or in part-time employment. Finally we include an indicator for respondents living in urban areas. Descriptive statistics for these variables are given in Table A.1 in the appendix.

\section{RESULTS}

Table 2 shows parameter estimates and standard errors for equation (13) under various model specifications. ${ }^{17}$ Columns (1) and (2) display results from our hierarchical model, without and with control variables, respectively. In both we find that increasing income distance from the national mean is inversely related to support for redistribution. The direct effect of inequality on preferences is considerably reduced when we include a range of individual- and state-level control variables. In fact, there is no statistically reliable main effect of inequality in specification (2). However, our central argument (part D in proposition 1) is concerned with the income-conditional effect of inequality, which is tested by our income-inequality interaction. Confirming our expectations, we find a positive effect, indicating that inequality matters more for the rich. The parameter estimate of this interaction is significant (in the statistical sense; we evaluate its substantive importance below).

\footnotetext{
${ }^{17}$ Appendix D shows an extended version of this table where we additionally include bootstrapped standard errors. Our results are not affected by this choice.
} 
Table 2: Income, inequality and redistribution preferences. Estimates and standard errors.

\begin{tabular}{lcccc}
\hline & $(1)$ & $(2)$ & $(3)$ & $(4)$ \\
\hline Income & -0.126 & -0.105 & -0.106 & -0.189 \\
& $(0.016)$ & $(0.016)$ & $(0.016)$ & $(0.020)$ \\
Inequality & 1.402 & 0.696 & 0.994 & 2.195 \\
& $(0.531)$ & $(0.501)$ & $(0.838)$ & $(1.140)$ \\
Incomexinequality & 0.209 & 0.208 & 0.210 & 0.379 \\
& $(0.058)$ & $(0.058)$ & $(0.059)$ & $(0.075)$ \\
Controls & no & yes & yes & yes \\
\hline Deviance & 22172 & 21718 & 21640 & - \\
BIC & 22409 & 22063 & 22448 & - \\
$\mathrm{N}$ & 19025 & 19025 & 19025 & 19025 \\
\hline Specifications: (1), (2): Random effects, maximum likelihood estimates, (3) Fixed effects, maximum likeli- \\
hood estimates, (4) Fixed effects, linear probability model.
\end{tabular}

Our empirical strategy exploits within-state changes in inequality. To make this more explicit, we estimate a fixed-effects version of our model in specification (3). ${ }^{18}$ Our results are remarkably similar. They again emphasize the fact that the effect of changing inequality is conditional on respondents' income distance. Finally, in specification (4) we employ a fixed-effects linear probability model, which uses all seven categories of the dependent variable instead of our support indicator variable. This specification, too, produces clear evidence for the conditional effect of inequality on preferences.

A stricter statistical test for our theoretical argument is provided by computing the marginal effect of a change in inequality conditional on income. Let $M E(Q \mid Y, X)$ denote the marginal effect of inequality, $Q$, conditional on income, $Y$, and controls $X$. When calculating marginal effects, it is common to set control variables to their sample mean, producing marginal effects for a hypothetical "typical" individual,

\footnotetext{
${ }^{18}$ This is an unconditional fixed-effects model, since there is no way to integrate state-specific constants out of the likelihood. It is well known that unconditional (or dummy variable) fixed-effects estimators for probit models are biased (Greene 2004) due to the incidental parameters problem (Neyman and Scott 1948). However, since our number of cases per state is reasonably large, we expect this not to be of major concern (see Katz 2001). In any case, we estimate a conditional fixed-effects model in specification (4).
} 
Table 3: Marginal effects

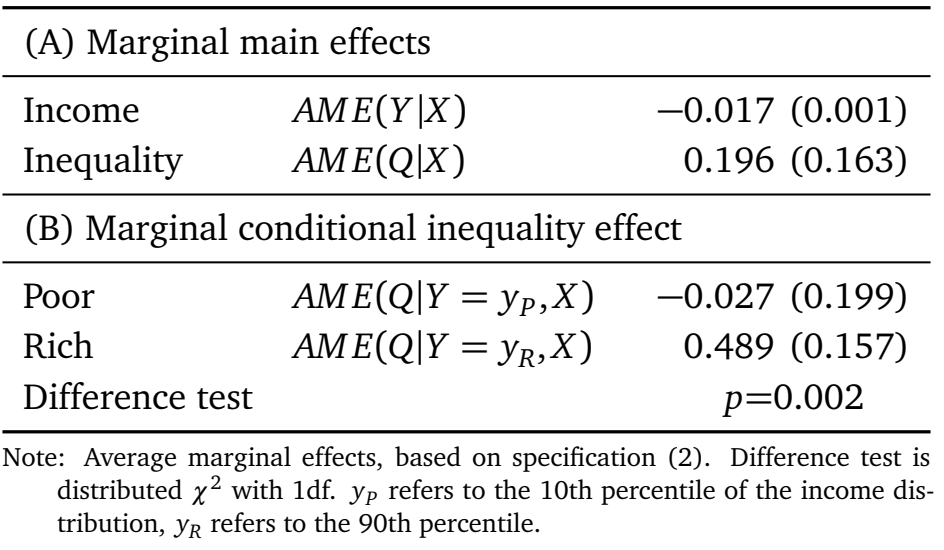

$M E(Q \mid Y=y, X=\bar{x})$. We opt for a clearer definition based on counterfactuals. ${ }^{19}$ What we are interested in are effects of changes in inequality (conditional on income) holding all else equal. Consequently, we calculate marginal effects for each case changing only inequality and income and keeping all other variables at values observed for that case: $M E_{i}\left(Q \mid Y=y, X=x_{i}\right)$. Average marginal effects are then simple averages over the marginal effects for each case, $A M E(Q \mid Y, X)=n^{-1} \sum_{i=1}^{n} M_{i}$.

Panel (A) of table 3 shows average marginal (unconditional) effects of inequality and income distance on the likelihood to support redistribution. These direct effects illustrate what we learned from Table 2. A marginal increase in income of all individuals leads to lower average support for redistribution, ceteris paribus. The main effect of inequality is not statistically distinguishable from zero.

Panel (B) of table 3 shows average marginal effects of inequality conditional on income. More precisely, we calculate the effect of a marginal change in inequality among the rich (those at the 90th percentile of the income distribution, around 58,000 dollars above the mean in constant dollars) and the poor (those at the 10th, around 38,000 dollars below the mean in constant dollars). We argued that an upward shift in inequality will mainly affect the rich, making them more supportive of redistribution. We find that a marginal change in inequality has little effect on the redistribution preferences of the poor, but has a marked and statistically significant effect for the rich.

\footnotetext{
${ }^{19}$ Hanmer and Kalkan (2013) provide a detailed discussion of the advantages of this strategy. See also Train (2009).
} 


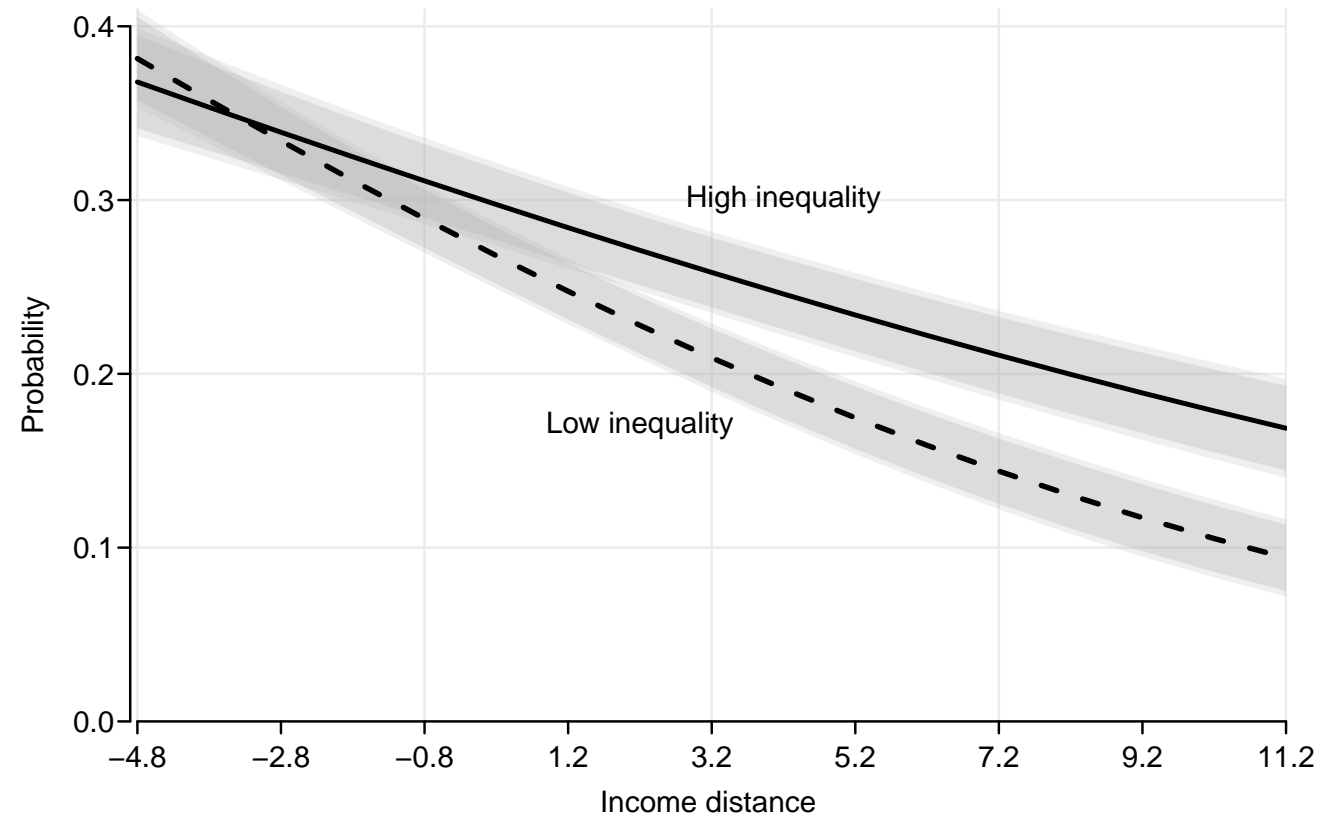

Figure 5: Average predicted probability of redistribution support as function of income distance in high and low inequality regions

As expected, we find that rising inequality increases support for redistribution among the rich. Before we present the substantive magnitude of this effect using predicted probabilities below, we calculate the difference in marginal effects between rich and poor, i.e. $A M E\left(Q \mid Y=y_{R}, X\right)-A M E\left(Q \mid Y=y_{P}, X\right)$. In other words, we test if the differential effect of a marginal change for rich and poor is statistically significant. ${ }^{20}$ We calculate a $\chi^{2}$ difference test, which shows that inequality does indeed affect the rich differently in a (statistically) significant way.

To illustrate the substantive role of inequality in perhaps a more intuitive way, Figure 5 shows the average predicted probability of redistribution support. ${ }^{21}$ In this figure, the only factors that change in the comparison of predicted probabilities are income distance to the mean (on the x-axis) and the two levels of macro inequality (the solid and dashed lines). High inequality refers to Atkinson index values at the

${ }^{20}$ The fact that we find a significant effect in one group, and a non-significant effect in the other, does not itself show that the difference is significant (cf. Gelman and Stern 2006).

${ }^{21}$ Average predicted probabilities are calculated similar to the average marginal effects described above. And they are, once again, based on specification (2) in Table 2. 
90th percentile of the state-level distribution (similar to that of Nevada and Florida in 2007), while low inequality refers to the 10th (as in Washington or Vermont in 1985). The results provide a clear picture of the correspondence between our theoretical argument (in Figure 2) and the empirical findings. While the poor are similarly likely to support redistribution in equal and unequal states, the rich are more likely to support redistribution in states characterized by high levels of inequality.

An alternative way to illustrate the effects found in Table 2 is offered in Figure 6 . In this figure, levels of macro inequality are now on the x-axis and the two distances to the mean are now represented by the solid (the rich, 90th percentile) and dashed (the poor, 10th percentile) lines. The predicted probabilities in this figure re-emphasize the main message in the paragraph above. For the poor, the level of macro inequality does not make much of a difference (although, within the confidence bounds, it is possible that their support for redistribution is slightly higher when macro inequality is high). Their likelihood to support redistribution fluctuates around a level close to 0.35. For the rich, on the other hand, the probability of supporting redistribution increases significantly as inequality grows from below 0.20 when inequality is at its lowest, to almost 0.30 when it is at its highest.

\section{ROBUSTNESS CHECKS}

We conduct a number of robustness checks in order to investigate the sensitivity of our results to alternative theoretical arguments. Below we summarize results from 12 specifications. In each we estimate the full model, but only present parameter estimates for $\gamma_{3} Q_{s t} y_{i s t}$, the income-inequality interaction, to save space.

Insurance As discussed in section $\mathrm{B}$, one prominent account of redistribution preferences is based on the idea of insurance motives. Forward-looking individuals possess information about their risk of becoming unemployed and the likely costs of finding a new job. These costs are a function of the specificity or non-transferability of their skills. Individuals in occupations with higher risk of unemployment and/or more specific skills thus have an incentive to use the welfare state as a provider of insurance (e.g., Iversen and Soskice 2001; Cusack et al. 2006). From this perspective, observing individuals who prefer higher levels of redistribution does not necessarily represent 


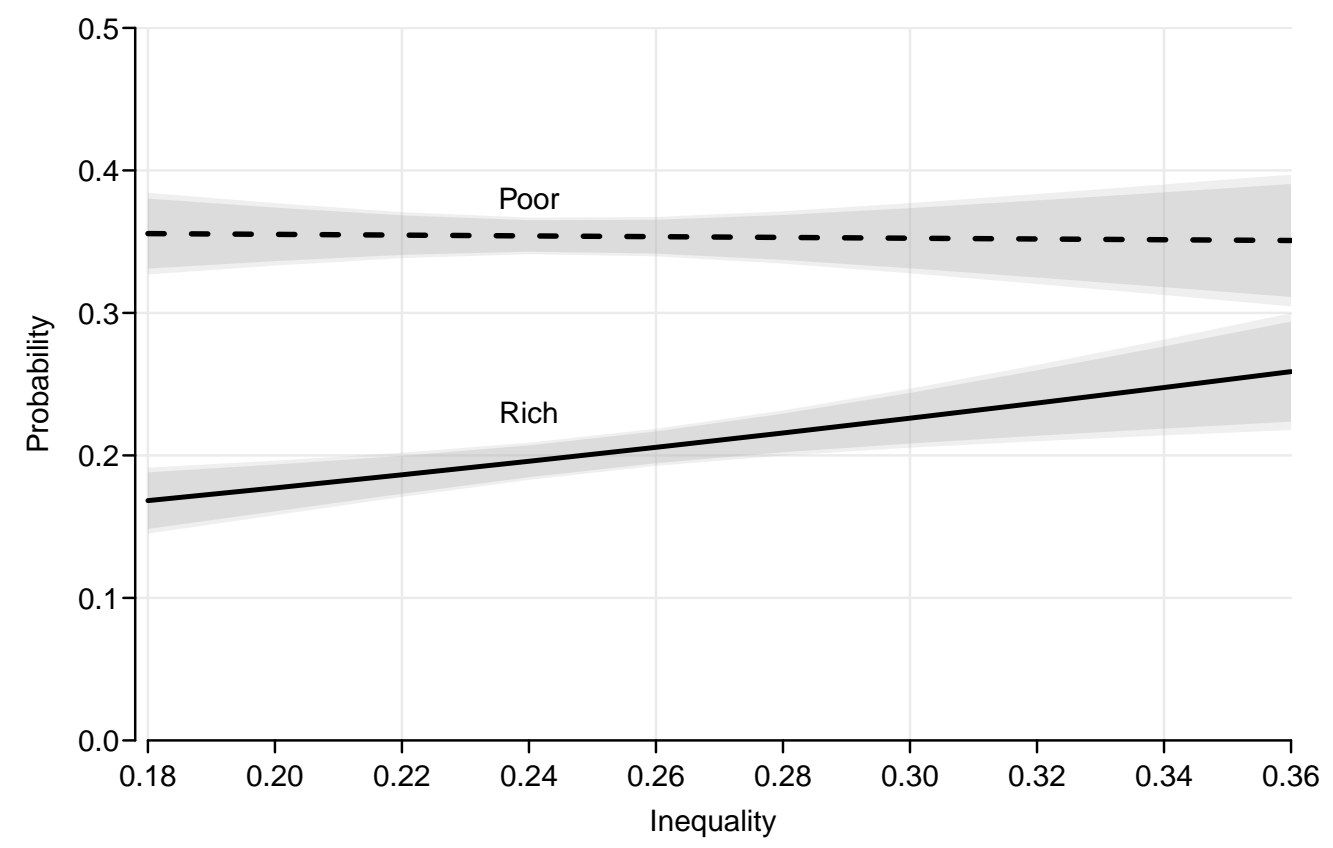

Figure 6: Average predicted probability of redistribution support as function of inequality among rich and poor

altruism - they might simply insure their future selves against the vagaries of the labor market.

We argue that insurance motives are compatible with our argument, which is not about levels of redistribution preferences, but differences in preferences between high and low inequality areas. We expect insurance factors to be orthogonal to our findings and capture insurance motives using two measures. Risk is captured by a variable which estimates unemployment rates by occupations, following Rehm (2011). The specificity or non-transferability of skills is captured by an encompassing measure of general and specific skills proposed by Fleckenstein et al. (2011). When we add these variables to our model in specifications (1) and (2) in Table 4, we find that our core result is indeed unchanged.

Urbanization \& race Although our analyses emphasize the state level, one may argue that we ignore political geography, i.e., the distinct preferences of individuals living in high-density urban areas (see, for example, Cho et al. 2006). As argued by Rodden (2010: 322), individuals may sort themselves into neighborhoods with 
Table 4: Robustness checks. Parameter estimates for income-inequality interaction

\begin{tabular}{|c|c|}
\hline Specification & $\gamma_{3} Q_{s t} y_{i s t}$ \\
\hline \multicolumn{2}{|l|}{ Insurance } \\
\hline (1) Skill specificity & $0.209(0.059)$ \\
\hline (2) Occupational unempl. & $0.174(0.066)$ \\
\hline \multicolumn{2}{|l|}{ Urbanization \& Race } \\
\hline (3) Population density & $0.207(0.058)$ \\
\hline (4) Nonwhite pop. share & $0.208(0.058)$ \\
\hline \multicolumn{2}{|l|}{ Further checks } \\
\hline (5) Industry effects & $0.208(0.059)$ \\
\hline (6) Gini (CPS) & $0.182(0.056)$ \\
\hline (7) Social class & $0.203(0.059)$ \\
\hline (8) Religion & $0.209(0.059)$ \\
\hline (9) State crime rate & $0.202(0.058)$ \\
\hline (10) State income & $0.208(0.058)$ \\
\hline (11) Ideology & $0.181(0.061)$ \\
\hline (12) Multiple imputation & $0.180(0.056)$ \\
\hline (13) Nonparametric $R^{a}$ & $0.171(0.069)$ \\
\hline
\end{tabular}

similar demographic, occupational, income, and ultimately political preferences. We addressed this concern by including in our main specification an individual-level survey variable which indicates if the respondent lives in an urban region (defined as cities with at least 50,000 inhabitants). As an additional check we include in specification (3) a state's population density (calculated from Census population estimates). Again, we find our results to be unchanged. Similarly, the racial heterogeneity of a state (as opposed to a respondent's race, which we include in our main model) might negatively affect individual's preferred levels of spending (see, for example, Luttmer 2001; Alesina and Glaeser 2004). We thus include a measure of racial heterogeneity (the state-level share of non-white population, calculated from the Current Population survey), we find our results to be robust in in Table 4's specification (4). 
Further checks Our results are also robust when accounting for sector specific preferences by including a set of industry fixed effects in specification (5). ${ }^{22}$ Specification (6) uses the Gini inequality measure calculated from the Current Population Survey instead of IRS tax returns. Our main result is confirmed. For reasons of parsimony we exclude a number of social factors such as religion and social class from our main model. While clearly important, we argue that these factors are orthogonal to the income-inequality nexus. Specifications (7) and (8) in Table 4 show that including a five-category social class measure as well as religiosity (church attendance) in the model leaves our results unchanged. ${ }^{23}$

An important regional feature that could drive our results is the level of crime (as a potential concern by the rich, unconnected to altruism, for the negative externalities of inequality). In specification (9) we use data from the Federal Bureau of Investigation's Uniform Crime Reporting database on total regional crime rates and find our core result unchanged. We also include state income per capita (calculated from the Current Population Survey) to control for the fact that states differ in levels of average income. Specification (10) shows that this does not impact our main finding.

Our main model does not include ideology since we consider redistribution preferences to be conceptualized as a more specific manifestation of ideology. Nonetheless, in specification (11) in table 4 we show that our results hold even when including a 7-point ideology measure from the GSS.

On a more technical note, specification (12) is estimated using 5 multiply imputed data sets (instead of list-wise deletion of missing cases), with multiple-imputation adjusted standard errors, while specification (13) allows for a flexible nonparametric random effects distribution via Dirichlet Process priors (for recent political science applications see, e.g.,Kyung et al. 2011; Stegmueller 2013). The model is estimated in a Bayesian framework, which also provides an additional robustness check for our multilevel specification. In both specifications, we find almost unchanged results.

\footnotetext{
${ }^{22}$ We use the US Census Bureau's industry classification at the 1-digit level.

${ }^{23}$ We employ a five category version of the Erikson-Goldthorpe class scheme: Service class I, Service class II, Routine non-manual occupations, Skilled workers, and Unskilled workers. Those who are self-employed are already included in our main model via an indicator variable.
} 


\section{CONCLUSION}

It is perhaps most meaningful to conclude this paper by first reminding the reader about our main findings and, more importantly, referring to the alternatives we find no evidence for. Our results strongly support the existence of "income-dependent altruism." The rich in more unequal places do support redistribution more than the rich in more equal places (while the poor's support for redistribution is much less affected by macro inequality). This paper's analyses provide limited support for alternative approaches to other-regarding preferences. Neither the "referencedependent inequity aversion" preferences proposed by Fehr and Schmidt (1999) nor the "fairness" preferences in Alesina and Angeletos (2005) seem to apply to the demand for redistribution in the US.

In the previous pages, we de-emphasized arguments about empathy and beliefs in a just world, but our analyses also introduce a degree of doubt about their relevance. In a significant contribution to the literature on redistribution, Lupu and Pontusson (2011) propose that macro-levels of equality are related to empathy. They argue that, because of social affinity, individuals will be inclined to have more similar redistribution preferences to those who are closer to them in terms of income distance. While Lupu and Pontusson emphasize skew (rather than Atkinson or Gini indices) and the position of the middle class, their argument implies that social affinity would make the rich have higher levels of support for redistribution as inequality decreases and they become closer to the middle class and the poor (the opposite of the predictions in this paper). A similar relationship would be expected by the approach that relates beliefs in a just world to redistribution preferences. To the extent that macro-levels of inequality are related to these beliefs (for example that inequality rewards the hard-working and punishes the lazy), we would observe lower levels of support for redistribution from the rich in states with higher inequality and a higher normative tolerance for it (Benabou and Tirole 2006; Alesina and Glaeser 2004). Our evidence fails to support these arguments.

Our research, finally, runs counter to a set of findings in the psychology literature about the influence of income on charitable giving and pro-social behavior. Using surveys conducted in the US, some authors find that lower income individuals give proportionally more to charitable causes than higher income ones (see for example, 
James and Sharpe 2007). ${ }^{24}$ These findings, however, are contested by research showing that the share of households giving to charity increases in income in both the United States (Andreoni 2006) and Great Britain (Pharoah and Tanner 1997). Other authors using experimental data find that subjective perceptions of one's social class rank in society promote generosity and charitable donations (see Piff et al. 2010). This paper does not address the side of altruism that concerns voluntary donations. ${ }^{25}$ But our results do indicate that, irrespective of charity, the rich are more likely to support government-based redistribution.

We will conclude by noting that, in some ways, this paper presents a somewhat unintuitive result (the rich are more supportive of redistribution in those states where inequality is highest). One might ask why we do find more inequality in precisely the places where the rich are more supportive of redistribution. We think this is an important question in need of a significant amount of further research. As McCarty and Pontusson (2009) note, models of the political economy of redistribution involve two separate propositions: there is a "demand" side, concerning the redistribution preferences of voters, and a "supply" side, concerning the aggregation of these preferences and the provision of policy. In this paper we have focused on the first proposition and ignored the second. It is germane, however, to ask whether these redistribution preferences have any political consequences. In a related paper "AUTHOR CITATION" answer this question in the affirmative. They show that in the US, redistribution preferences are a significant determinant of voting. More concretely, they demonstrate that income distance matters to voting mainly through its effect on redistribution preferences. Preferences alone explain half of the total effect of income on vote choice. While more research on the supply side of redistribution is clearly needed (a number of factors may intermediate between voting and the provision of redistributive policy), the political relevance of this paper's findings should not be ignored.

\footnotetext{
${ }^{24}$ This research has found wide resonance in the popular press. See Greve (2009) or Johnston (2005).

${ }^{25}$ The relationship between income and charity giving in OECD countries is a complicated one and not always a good illustration of altruism, as the tax benefits of giving (often increasing with income) are difficult to assess.
} 


\section{REFERENCES}

Alesina, Alberto and Angeletos, George-Marios. 2005. "Fairness and Redistribution." American Economic Review 95 (4): 960-980.

Alesina, Alberto and Giuliano, Paola. 2011. "Preferences for Redistribution." In Jess Benhabib, Alberto Bisin, and Matthew O. Jackson, eds., "Handbook of Social Economics," San Diego: North-Holland. 93-131.

Alesina, Alberto and Glaeser, Edward L. 2004. Fighting Poverty in the US and Europe. A world of Difference. Oxford: Oxford University Press.

Alesina, Alberto and La Ferrara, Eliana. 2005. "Preferences for Redistribution in the Land of Opportunities." Journal of Public Economics 89 (5): 897-931.

Almlund, Mathilde, Duckworth, Angela Lee, Heckman, James J, and Kautz, Tim. 2011. "Personality Psychology and Economics." In Eric A Hanushek, Stephen Machin, and Ludger Woessmann, eds., "Handbook of the Economics of Education," Elsevier. 1-181.

Alt, James and Iversen, Torben. 2013. "Inequality, Labor Market Segmentation, and Preferences for Redistribution." Working paper.

Andreoni, James. 1989. "Giving with Impure Altruism: Applications to Charity and Ricardian Equivalence.” Journal of Political Economy 97 (6): 1447-1458.

Andreoni, James. 1990. "Impure Altruism and Donations to Public Goods: A Theory of Warm-Glow Giving." The Economic Journal 100 (401): 464-477.

Andreoni, James. 2006. "Philanthropy." Handbook of the economics of giving, altruism and reciprocity 2: 1201-1269.

Atkinson, Anthony B. 1970. "On the Measurement of Inequality." Journal of Economic Theory 2: 244-263.

Atkinson, Anthony B, Piketty, Thomas, and Saez, Emmanuel. 2011. "Top incomes in the long run of history." Journal of Economic Literature 49 (1): 3-71.

Bartels, Larry M. 2009. Unequal democracy: The political economy of the new gilded age. Princeton University Press.

Benabou, Roland and Tirole, Jean. 2006. "Belief in a Just World and Redistributive Politics." Quarterly Journal of Economics 121 (2): 699-746. 
Bureau of Labor Statistics. 1992. "Measurement of Unemployment in States and Local Areas." In "BLS Handbook of Methods," Bureau of Labor Statistics, chapter 4.

Charness, Gary and Rabin, Matthew. 2002. "Understanding social preferences with simple tests." The Quarterly Journal of Economics 117 (3): 817-869.

Cho, Wendy K Tam, Gimpel, James G, and Dyck, Joshua J. 2006. "Residential Concentration, Political Socialization, and Voter Turnout." The Journal of Politics 68 (01): 156-167.

Cowell, Frank A. 2000. "Measurement of inequality." In Anthony B. Atkinson and Francois Bourguignon, eds., "Handbook of income distribution," Elsevier, volume 1. 87-166.

Cowell, Frank A and Mehta, Fatemeh. 1982. "The estimation and interpolation of inequality measures." Review of Economic Studies 49 (2): 273-290.

Cusack, Thomas, Iversen, Torbern, and Rehm, Philipp. 2006. "Risks At Work: The Demand And Supply Sides Of Government Redistribution." Oxford Review of Economic Policy 22 (3): 365-389.

DellaVigna, Stefano. 2009. "Psychology and Economics: Evidence from the Field." Journal of Economic Literature 47 (2): 315-372.

Fehr, E and Schmidt, K M. 1999. "A Theory of Fairness, Competition, and Cooperation." Quarterly Journal of Economics 114 (3): 817-868.

Fehr, Ernst and Gächter, Simon. 2000. "Fairness and retaliation: The economics of reciprocity." Journal of Economic Perspectives 14 (3): 159-181.

Fehr, Ernst and Schmidt, K M. 2006. "The Economics of Fairness, Reciprocity, and Altruism: Experimental Evidence and New Theories." In Serge-Christophe Kolm and Jean Mercier Ythier, eds., "Handbook of the Economics of Giving, Reciprocity, and Altruism," Elsevier. 615-691.

Fleckenstein, T., Saunders, A. M., and Seeleib-Kaiser, M. 2011. "The Dual Transformation of Social Protection and Human Capital: Comparing Britain and Germany." Comparative Political Studies 44 (12): 1622-1650.

Fong, Christina. 2001. "Social preferences, self-interest, and the demand for redistribution." Journal of Public Economics 82 (2): 225-246. 
Frank, Mark W. 2009. "Inequality and growth in the United States: Evidence from a new state-level panel of income inequality measures." Economic Inquiry 47 (1): 55-68.

Gelman, Andrew and Stern, Hal. 2006. "The Difference between 'Significant' and 'Not Significant' is not Itself Statistically Significant." The American Statistician 60 (4): 328-331.

Greene, William. 2004. "The behaviour of the maximum likelihood estimator of limited dependent variable models in the presence of fixed effects." Econometrics Journal 7: 98-119.

Greene, William H. 2002. Econometric Analysis. New Jersey: Prentice Hall.

Greve, F. 2009. "America's poor are its most generous." The Seattle Times. Retrieved from http://seattletimes. nwsource. com.

Hacker, Jacob S and Pierson, Paul. 2011. Winner-Take-All Politics: How Washington Made the Rich Richer-and Turned Its Back on the Middle Class. Simon and Schuster. Hanmer, Michael J and Kalkan, Kerem Ozan. 2013. "Behind the Curve: Clarifying the Best Approach to Calculating Predicted Probabilities and Marginal Effects from Limited Dependent Variable Models." American Journal of Political Science 57 (1): 263-277.

Hout, M. 2004. "Getting the most out of the GSS income measures." GSS Methodological Report 101.

Iversen, Torben and Soskice, David. 2001. "An Asset Theory of Social Policy Preferences." American Political Science Review 95 (4): 875-893.

James, Russell N and Sharpe, Deanna L. 2007. "The nature and causes of the Ushaped charitable giving profile." Nonprofit and Voluntary Sector Quarterly 36 (2): 218-238.

Jiang, Jiming. 2007. Linear and Generalized Linear Models Mixed Models and Their Applications. New York: Springer.

Johnston, David Cay. 2005. "Study shows the superrich are not the most generous." The New York Times.

Katz, Ethan. 2001. "Bias in conditional and unconditional fixed effects logit estimation." Political Analysis 9 (4): 379-384. 
Keely, Louise C and Tan, Chih Ming. 2008. "Understanding preferences for income redistribution." Journal of Public Economics 92 (5): 944-961.

Kopczuk, Wojciech, Saez, Emmanuel, and Song, Jae. 2010. "Earnings Inequality and Mobility in the United States: Evidence from Social Security Data since 1937." Quarterly Journal of Economics 125 (1): 91-128.

Kuziemko, Ilyana, Buell, Ryan W, Reich, Taly, and Norton, Michael I. 2014. "Last-Place Aversion: Evidence and Redistributive Implications." The Quarterly Journal of Economics 129 (1): 105-149.

Kyung, Minjung, Gill, Jeff, and Casella, George. 2011. "New findings from terrorism data: Dirichlet process random-effects models for latent groups." Journal of the Royal Statistical Society C 60 (5): 701-721.

Lambert, Peter. 1989. The Distribution and Redistribution of Income. Oxford, UK: Basil Blackwell.

Lü, Xiaobo and Scheve, Kenneth. 2014. "Self-Centered Inequity Aversion and the Mass Politics of Taxation." Working paper.

Lupu, Noam and Pontusson, Jonas. 2011. "The Structure of Inequality and the Politics of Redistribution." American Political Science Review 105 (2): 316-336.

Luttmer, Erzo F P. 2001. "Group loyalty and the taste for redistribution." Journal of Political Economy 109 (3): 500-528.

Mas-Colell, Andreu, Whinston, Michael Dennis, Green, Jerry R, et al. 1995. Microeconomic theory. Oxford: Oxford University Press.

McCarty, Nolan and Pontusson, Jonas. 2009. "The Political Economy of Inequality and Redistribution." In Wiemer Salverda, Brian Nolan, and Timothy M Smeeding, eds., "The Oxford Handbook of Economic Inequality," Oxford: Oxford University Press. 665-692.

McCarty, Nolan, Poole, Keith T, and Rosenthal, Howard. 2008. Polarized America: The Dance of Ideology and Unequal Riches. The MIT Press.

Moene, Kark Ove and Wallerstein, Michael. 2001. "Inequality, Social Insurance and Redistribution." American Political Science Review 95 (4): 859-874.

Neyman, Jerzy and Scott, Elizabeth L. 1948. "Consistent estimates based on partially consistent observations." Econometrica 16 (1): 1-32. 
Pharoah, Cathy and Tanner, Sarah. 1997. "Trends in charitable giving." Fiscal Studies 18 (4): 427-443.

Piff, Paul K, Kraus, Michael W, Côté, Stéphane, Cheng, Bonnie Hayden, and Keltner, Dacher. 2010. "Having less, giving more: the influence of social class on prosocial behavior." Journal of personality and social psychology 99 (5): 771.

Pratt, John W. 1964. "Risk aversion in the small and in the large." Econometrica 32 (1): 122-136.

Rabe-Hesketh, Sophia and Skrondal. 2008. "Generalized linear mixed effects models." In Garret Fitzmaurice, Marie Davidian, Geert Verbeke, and Geert Molenberghs, eds., "Longitudinal Data Analysis: A Handbook of Modern Statistical Methods," Boca Raton: Chapman \& Hall. 79-106.

Rabe-Hesketh, Sophia, Skrondal, Anders, and Pickles, Andrew. 2005. "Maximum likelihood estimation of limited and discrete dependent variable models with nested random effects." Journal of Econometrics 128 (2): 301-323.

Rehm, Philipp. 2011. "Risk Inequality and the Polarized American Electorate." British Journal of Political Science 41 (2): 363-387.

Rodden, Jonathan. 2010. "The Geographic Distribution of Political Preferences." Annual Review of Political Science 13 (1): 321-340.

Rushton, Philippe J, Chrisjohn, Roland D, and Cynthia Fekken, G. 1981. "The altruistic personality and the self-report altruism scale." Personality and individual differences 2 (4): 293-302.

Shayo, Moses. 2009. "A Model of Social Identity with an Application to Political Economy: Nation, Class, and Redistribution." American Political Science Review 103 (2): 147-174.

Shorrocks, Anthony F. 1980. "The class of additively decomposable inequality measures." Econometrica 48 (3): 613-625.

Stegmueller, Daniel. 2013. "Modeling dynamic preferences: a Bayesian robust dynamic latent ordered probit model." Political Analysis 21 (3): 314-333.

Train, Kenneth. 2009. Discrete Choice Models with Simulation. Cambridge: Cambridge University Press. 
Tricomi, Elizabeth, Rangel, Antonio, Camerer, Colin F, and O’Doherty, John P. 2010. "Neural evidence for inequality-averse social preferences." Nature 463 (7284): 1089-1091. 
A. [ONLINE] APPENDIX

\section{A. Proofs \\ Proof of Lemma 1}

We show that $\Omega=u[\bar{c}(1-Q)]=u\left(c_{e}\right)$, where

$$
\bar{c}(1-Q)
$$

is the "abbreviated social welfare function." This equivalence, well-known in the welfare economics literature, is reproduced here for the convenience of the reader. For further discussion, see Atkinson (1970) and Lambert (1989: 109-136).

To begin, let $c_{e}=(1-\tau) y_{e}+T$ be the level of disposable income that represents the average utility given by the social welfare function, or

$$
\frac{1}{n} \sum_{j=1}^{n} u\left(c_{j}\right)=\frac{1}{n} n u\left(c_{e}\right)=u\left(c_{e}\right) .
$$

By Jensen's Inequality, we know that $c_{e} \in(0, \bar{c})$ and therefore that $y_{e} \in(0, \bar{y})$. In fact, Atkinson (1970) characterizes this level of income as "equally distributed equivalent income," and it is the basic building block of the Atkinson Index. It represents the level of income that if held by every individual would give that society the same level of welfare as would obtain with any given allocation of unequally distributed incomes. The Atkinson index is constructed as:

$$
Q=1-\frac{c_{e}}{\bar{c}} .
$$

Since $c_{e}$ is strictly below mean income, this expression is always positive and always between 0 and 1 . Indeed, as inequality increases, social welfare decreases as does $c_{e}$. This will be a useful property for subsequent proofs.

Next, using the specific functional form for CRRA preferences in equation (6), we can rewrite equation (A.2) as:

$$
\frac{c_{e}^{1-\epsilon}}{1-\epsilon}=\frac{1}{n} \sum_{j=1}^{n} \frac{c_{j}^{1-\epsilon}}{1-\epsilon}
$$


Rearranging this equation in terms of $c_{e}$, we obtain:

$$
c_{e}=\left(\frac{1}{n} \sum_{j=1}^{n} c_{j}^{1-\epsilon}\right)^{1 /(1-\epsilon)}
$$

Then, substituting this expression into the preliminary Atkinson Index in equation (A.3), we obtain:

$$
Q=1-\frac{1}{\bar{c}}\left(\frac{1}{n} \sum_{i=1}^{n} c_{j}^{1-\epsilon}\right)^{1 /(1-\epsilon)}
$$

which is equivalent to the expression given in equation (8).

Finally, to recover the social welfare function, substitute the Atkinson Index in (A.6) into the abbreviated social welfare function (A.1) and then substitute the result into the CRRA preferences in equation (6). The result is $\Omega$. Hence, we have $\Omega=u[\bar{c}(1-Q)]=u\left(c_{e}\right)$.

\section{Proof of Proposition 1}

First, we prove Part (A). The individual's problem is to choose the tax rate that maximizes her social utility function, given by equation (4):

$$
\max _{\tau \in[0,1]} V=(1-\delta) u\left(c_{i}\right)+\delta u\left(c_{e}\right)
$$

subject to the government budget constraint in equation (2) and the individual's own budget constraint in equation (3). The first-order condition for this problem gives the preferred level of redistribution for each individual $i$, which we will term $\tau_{i}^{*}$ :

$$
(1-\delta) u^{\prime}\left(c_{i}\right)\left[\left(1-\tau_{i}^{*}\right) \bar{y}-y_{i}\right]+\delta u^{\prime}\left(c_{e}\right)\left[\left(1-\tau_{i}^{*}\right) \bar{y}-y_{e}\right]=0
$$

The second-order condition is given by:

$$
\begin{aligned}
\frac{\partial^{2} V}{\partial \tau^{2}} \equiv \sigma\left(\tau_{i}^{*}, y_{i}, y_{e}\right)=(1-\delta)\{ & u^{\prime \prime}\left(c_{i}\right)\left[(1-\tau) \bar{y}-y_{i}\right]^{2}-u^{\prime}\left(c_{i}\right) \bar{y} \\
& +\delta\left\{u^{\prime \prime}\left(c_{e}\right)\left[(1-\tau) \bar{y}-y_{e}\right]^{2}-u^{\prime}\left(c_{e}\right) \bar{y}<0\right.
\end{aligned}
$$


which is unambiguously negative.

Next, we show that $\tau_{i}^{*} \in[0,1)$. Rearrange the first-order condition as:

$$
\tau_{i}^{*}=\left(1-\frac{y_{i}}{\bar{y}}\right)+\frac{\delta}{1-\delta}\left(\frac{c_{i}}{c_{e}}\right)^{\epsilon}\left[\left(1-\tau_{i}^{*}\right)-\frac{y_{e}}{\bar{y}}\right]
$$

If $\delta=0$, that is, if individuals are not altruistic, then individual $i$ 's optimal choice of redistribution is $\tau_{i}^{*}=1-y_{i} / \bar{y}$, which is a familiar result for self-interested preferences. In this case, preferences for redistribution are clearly decreasing in income, with $\tau_{i}^{*}$ going from 1 to 0 as income goes from 0 to $\bar{y}$. Compare this to altruistic individuals, $\delta>0$. Setting $\tau=0$, equation (A.10) can be rewritten as:

$$
\frac{\delta}{1-\delta}\left(\frac{y_{i}}{y_{e}}\right)^{\epsilon}=-\frac{\left(\bar{y}-y_{i}\right)}{\left(\bar{y}-y_{e}\right)}
$$

Since the left-hand side is positive, this condition requires $y_{i}>\bar{y}$. Define the value of $y_{i}$ that satisfies this equation as $\hat{y}$. Hence, $\hat{y}>\bar{y}$, as claimed. Notice also that $\hat{y}$ is potentially quite large, especially as inequality increases: $y_{e} \rightarrow 0$. Finally, the maximum level of redistribution preferred by any individual is always less than one. Setting $\tau=1$ in equation (A.10), we get

$$
\frac{\delta}{1-\delta}=-\left(\frac{y_{i}}{y_{e}}\right)
$$

which is never satisfied.

Further exploration of equation (A.10) provides some additional important insights. First, let $\tau_{e}^{*}$ be the level of redistribution that maximizes social welfare, $\Omega=u\left(c_{e}\right)$. The value of $\tau_{e}^{*}$ is such that the first-order condition for maximizing social welfare equals zero, which is $\left(1-\tau_{e}^{*}\right)=y_{e} / \bar{y}$. Evaluated at $\tau_{e}^{*}$, the second expression on the righthand side of equation (A.10) becomes zero, so equation (A.10) becomes $\tau_{e}^{*}=1-y_{i} / \bar{y}$. Clearly, the level of individual income that satisfies this expression is $y_{e}$. Hence, an individual with income $y_{i}=y_{e}$ prefers the level of redistribution that maximizes social welfare. Furthermore, along with Part (B) below, this also implies that for $y_{i}>y_{e}$, we have $\tau_{i}^{*}<\tau_{e}^{*}$ and thus $\left(1-\tau_{i}^{*}\right)-y_{e} / \bar{y}>0$. That is, for $y_{i}>y_{e}$, an individual prefers a level of taxes and transfers such that the marginal benefit of reducing inequality exceeds its cost. In other words, individuals with income above the equally distributed 
equivalent prefer less redistribution than social welfare demands, and hence social welfare is positive and increasing at this level of redistribution. However, this also means that for $y_{i}>y_{e}$, an individual prefers more redistribution than if she were purely self-interested. To see this, evaluate equation (A.10) for a self-interested individual (i.e., $\delta=0$ ) with income $y_{i}>y_{e}$. This implies that $\left(1-\tau_{i}^{*}\right)-y_{i} / \bar{y}=0$. Compared to an altruistic individual $(\delta>0)$, this makes the second term on the right-hand side of (A.10) positive, because social welfare is increasing for $\tau_{i}^{*}<\tau_{e}^{*}$, which implies that $\tau_{i}^{*}\left(y_{i}>y_{e}, \delta>0\right)>\tau_{i}^{*}\left(y_{i}>y_{e}, \delta=0\right)$. Because this is true, this also implies that for an altruistic individual we have $\left(1-\tau_{i}^{*}\right)-y_{i} / \bar{y}<0$. That is, the marginal benefit of redistribution to an individual's material self-interest is lower than its cost. In other words, relatively well-off individuals sacrifice some material self- interest in order to satisfy their altruistic preferences for reducing inequality. An analogous argument holds for $y_{i}<y_{e}$. However, these cases require choosing more redistribution than social welfare requires, $\left(1-\tau_{i}^{*}\right)-y_{e} / \bar{y}<0$. Further, this means that the second term on the right-hand side of equation (A.10) is now negative, which implies that an individual with $y_{i}<y_{e}$ prefers less redistribution than self-interest demands: $\left(1-\tau_{i}^{*}\right)-y_{i} / \bar{y}>0$. To summarize, individuals with income below the equally distributed equivalent $\left(y_{i}<y_{e}\right)$ want less redistribution than they would if they were purely self-interested, but more redistribution than is socially optimal. In contrast, individuals with income above the equally distributed equivalent $\left(y_{i}>y_{e}\right)$, prefer more redistribution than if they were purely self-interested but less than is socially optimal.

Second, we prove Part (B), that an individual $i$ 's preferred level of redistribution $\tau_{i}^{*}$ is decreasing in individual income $y_{i}$. Formally, we seek to demonstrate that $\frac{\partial \tau_{i}^{*}}{\partial y_{i}}<0$. Totally differentiating the first-order condition in equation (A.8), we obtain

$$
\frac{d \tau_{i}^{*}}{d y_{i}}=-\frac{(1-\delta)\left\{u^{\prime \prime}\left(c_{i}\right)\left[(1-\tau) \bar{y}-y_{i}\right](1-\tau)-u^{\prime}\left(c_{i}\right)\right\}}{\sigma\left(\tau_{i}^{*}, y_{i}, y_{e}\right)}
$$

Since the expression in the denominator is negative, the sign of the derivative depends on the sign of the numerator. For $(1-\tau) \bar{y} \geq y_{i}$, the numerator is clearly negative. For $(1-\tau) \bar{y}<y_{i}$, the numerator is negative if the following condition holds: $u^{\prime \prime}\left(c_{i}\right)\left[(1-\tau) \bar{y}-y_{i}\right](1-\tau)-u^{\prime}\left(c_{i}\right)<0$. This condition reduces to 
$(1-\epsilon) y_{i}+\epsilon(1-\tau) \bar{y}+T /(1-\tau)>0$, which is true for all $\epsilon \in(0,1)$, all $y_{i} \in[0, \infty)$, and all $\tau \in[0,1]$. Hence, we have $\frac{\partial \tau_{i}^{*}}{\partial y_{i}}<0$. This proves Part (B).

Third, we prove Part (C). Part (C) states that an individual $i$ 's preferred level of redistribution $\tau_{i}^{*}$ is increasing in inequality $Q$. Formally, we demonstrate that $\frac{\partial \tau_{i}^{*}}{\partial Q}>0$. From Lemma 1, we can express a change in inequality as an increase in $Q: y_{e}=Q_{0}-Q$. Totally differentiating the first-order condition in equation (A.8), we obtain

$$
\frac{d \tau_{i}^{*}}{d Q}=-\frac{\delta\left\{-u^{\prime \prime}\left(c_{e}\right)\left[(1-\tau) \bar{y}-y_{e}\right](1-\tau)+u^{\prime}\left(c_{e}\right)\right\}}{\sigma\left(\tau_{i}^{*}, y_{i}, y_{e}\right)}
$$

Once again, since the expression in the denominator is negative, the sign of the derivative depends on the sign of the numerator. The numerator is clearly positive for $(1-\tau) \bar{y} \geq y_{e}$. For $(1-\tau) \bar{y} \leq y_{e}$, the expression in the numerator is positive if the following condition holds: $-u^{\prime \prime}\left(c_{e}\right)\left[(1-\tau) \bar{y}-y_{e}\right](1-\tau)+u^{\prime}\left(c_{e}\right)>0$. This condition reduces to $(1-\epsilon) y_{e}+\epsilon(1-\tau) \bar{y}+T /(1-\tau)>0$, which is true for all $\epsilon \in(0,1)$, all $y_{e} \in[0, \bar{y}]$, and all $\tau \in[0,1]$. Hence, we have $\frac{\partial \tau_{i}^{*}}{\partial Q}>0$.

Fourth, we prove Part (D). Part (D) states that the effect of an increase in inequality $Q$ on an individual $i$ 's preferred level of redistribution $\tau_{i}^{*}$ is increasing in individual income $y_{i}$. Formally, this is equivalent to $\frac{\partial^{2} \tau_{i}^{*}}{\partial Q \partial y_{i}} \geq 0$. Furthermore, this will be true if and only if $\epsilon>0$, otherwise $\frac{\partial^{2} \tau_{i}^{*}}{\partial Q \partial y_{i}}=0$. We demonstrate this second claim first. Using the version of the first-order condition in equation (A.10), set $\epsilon=0$. We can then rewrite (A.10) as:

$$
\tau_{i}^{*}=(1-\delta)\left(1-\frac{y_{i}}{\bar{y}}\right)+\delta\left(1-\frac{y_{e}}{\bar{y}}\right)
$$

It is immediate from this that $\frac{\partial \tau_{i}^{*}}{\partial Q}=\frac{\delta}{\bar{y}}$ and therefore that $\frac{\partial^{2} \tau_{i}^{*}}{\partial Q \partial y_{i}}=0$. This proves that $\epsilon \neq 0$ is a necessary condition for $\frac{\partial^{2} \tau_{i}^{*}}{\partial Q \partial y_{i}}>0$. Establishing the rest of the proof will demonstrate sufficiency.

We begin by showing that $\frac{\partial^{2} \tau_{i}^{*}}{\partial Q \partial y_{i}}>0$ for all $y_{i} \in\left[0, y_{e}\right)$. By factoring out $\delta c_{e}^{-\epsilon}$ from the numerator and denominator, rewrite the expression for $\partial \tau_{i}^{*} / \partial Q$ from equation (A.14) as:

$$
\frac{d \tau_{i}^{*}}{d Q}=\frac{A}{M B+C}
$$

where

$$
A=\frac{\epsilon\left[(1-\tau) \bar{y}-y_{e}\right](1-\tau)}{c_{e}}+1>0
$$




$$
\begin{gathered}
M=\left(\frac{1-\delta}{\delta}\right)\left(\frac{c_{e}}{c_{i}}\right)^{\epsilon}>0 \\
B=\frac{\epsilon\left[(1-\tau) \bar{y}-y_{i}\right]^{2}}{c_{i}}+\bar{y}>0
\end{gathered}
$$

and

$$
C=\frac{\epsilon\left[(1-\tau) \bar{y}-y_{e}\right]^{2}}{c_{e}}+\bar{y}>0
$$

We need to show that the following is true:

$$
\frac{\partial^{2} \tau_{i}^{*}}{\partial Q \partial y_{i}}=\frac{\frac{\partial A}{\partial y_{i}}(M B+C)-A\left(\frac{\partial M}{\partial y_{i}} B+M \frac{\partial B}{\partial y_{i}}+\frac{\partial C}{\partial y_{i}}\right)}{(M B+C)^{2}}>0
$$

Differentiating $A$ with respect to $y_{i}$, we obtain:

$$
\frac{\partial A}{\partial y_{i}}=-\left(\frac{\epsilon\left[(1-\tau) \bar{y}-y_{e}\right]+\epsilon(1-\tau) \bar{y}}{c_{e}}+\frac{\epsilon(1-\tau)\left[(1-\tau) \bar{y}-y_{e}\right]^{2}}{c_{e}^{2}}\right) \frac{\partial \tau_{i}^{*}}{\partial y_{i}}
$$

For $y_{i}<y_{e}$, we have $\left[(1-\tau) \bar{y}-y_{e}\right]<0$, which makes the first term within the parentheses ambiguous and the second term positive. However, since $y_{i}<y_{e}$ makes the first term in $A$ negative and $\left[(1-\tau) \bar{y}-y_{e}\right] \rightarrow 0$ as $y_{i} \rightarrow y_{e}$, the expression must be positive (since $-\partial \tau_{i}^{*} / \partial y_{i}>0$ ). This implies $\frac{\partial A}{\partial y_{i}}(M B+C)>0$. Next, we have:

$$
\begin{aligned}
\frac{\partial M}{\partial y_{i}}=\epsilon\left(\frac{1-\delta}{\delta}\right)\left(\frac{c_{e}}{c_{i}}\right)^{\epsilon} & \\
\times & {\left[\left(\frac{\left[\left(1-\tau_{i}^{*}\right) \bar{y}-y_{e}\right]}{c_{e}}-\frac{\left[\left(1-\tau_{i}^{*}\right) \bar{y}-y_{i}\right]}{c_{i}}\right) \frac{\partial \tau_{i}^{*}}{\partial y_{i}}-\frac{\left(1-\tau_{i}^{*}\right)}{c_{i}}\right] . }
\end{aligned}
$$

For $y_{i}<y_{e}$, we have $\left[\left(1-\tau_{i}^{*}\right) \bar{y}-y_{i}\right]>0$ and $\left[\left(1-\tau_{i}^{*}\right) \bar{y}-y_{e}\right]<0$. This makes the parenthetical term within brackets positive. However, because the gross income effect dominates the redistribution effect, the negative term, $-\left(1-\tau_{i}^{*}\right) / c_{i}$, dominates the positive term within parentheses. This makes the whole expression negative and therefore, $-A \frac{\partial M}{\partial y_{i}} B>0$. 
Next, we have:

$$
\begin{aligned}
& \frac{\partial B}{\partial y_{i}}=-\frac{2 \epsilon\left[(1-\tau) \bar{y}-y_{i}\right]}{c_{i}}-\frac{\epsilon\left[(1-\tau) \bar{y}-y_{i}\right]^{2}(1-\tau)}{c_{i}} \\
&-\left(\frac{2 \epsilon\left[(1-\tau) \bar{y}-y_{i}\right] \bar{y}}{c_{i}}+\frac{\epsilon\left[(1-\tau) \bar{y}-y_{i}\right]^{3}}{c_{i}^{2}}\right) \frac{\partial \tau_{i}^{*}}{\partial y_{i}}
\end{aligned}
$$

Once again, we have $\left[(1-\tau) \bar{y}-y_{i}\right]>0$, which makes the first two terms negative, but the second two terms positive, since $-\partial \tau_{i}^{*} / \partial y_{i}>0$. However, since in $B[(1-\tau) \bar{y}-$ $\left.y_{i}\right]^{2}>0$ and $\left[(1-\tau) \bar{y}-y_{i}\right] \rightarrow 0$, the first negative "income" effect must dominate the second, positive "tax" effect. Therefore, $-A M \frac{\partial B}{\partial y_{i}}>0$.

Finally, we have

$$
\frac{\partial C}{\partial y_{i}}=-\left(\frac{2 \epsilon\left[(1-\tau) \bar{y}-y_{e}\right] \bar{y}}{c_{e}}+\frac{\epsilon\left[(1-\tau) \bar{y}-y_{e}\right]^{3}}{c_{e}^{2}}\right) \frac{\partial \tau_{i}^{*}}{\partial y_{i}}
$$

which, since $\left[(1-\tau) \bar{y}-y_{e}\right]<0$ for $y_{i}<y_{e}$ must be negative. Therefore, $-A \frac{\partial C}{\partial y_{i}}>0$ and we conclude that equation (A.17) is positive.

Observe that for $y_{i}=y_{e},\left[(1-\tau) \bar{y}-y_{e}\right]=0$ and $\left[(1-\tau) \bar{y}-y_{i}\right]=0$. Using this fact, we get $d \tau_{i}^{*} / d Q=\delta / \bar{y}$. Hence at $y_{i}=y_{e}, \frac{\partial^{2} \tau_{i}^{*}}{\partial Q \partial y_{i}}=0$.

For $y_{i} \in\left(y_{e}, \hat{y}\right]$, it is easiest to show that $\frac{\partial^{2} \tau_{i}^{*}}{\partial Q \partial y_{i}}>0$ by making an analogous argument using the expression for $\partial \tau_{i}^{*} / \partial y_{i}$ given in equation (A.13). In that case, we show that $\frac{\partial^{2} \tau_{i}^{*}}{\partial y_{i} \partial Q}>0$. Since $\frac{\partial^{2} \tau_{i}^{*}}{\partial y_{i} \partial Q}$ and $\frac{\partial^{2} \tau_{i}^{*}}{\partial Q \partial y_{i}}$ are equivalent, this proves that $\frac{\partial^{2} \tau_{i}^{*}}{\partial Q \partial y_{i}} \geq 0$ for all $y_{i} \in[0, \infty)$ and this concludes the proof. 


\section{B. Deriving the full estimating equation}

From the first order condition of individual i's utility function in (4) we derive the theoretical function $\tau_{i}^{*}\left(y_{i}, Q\right)$, which represents $i$ 's preferred level of redistribution, $\tau_{i}^{*}$, given $i$ 's income, $y_{i}$, and the level of inequality, $Q$. The second-order Taylor expansion of $\tau_{i}^{*}\left(y_{i}, Q\right)$ is given by:

$$
\tau_{i}^{*}=x+\frac{\partial \tau_{i}^{*}}{\partial y_{i}} y_{i}+\frac{\partial \tau_{i}^{*}}{\partial Q} Q+\frac{\partial^{2} \tau_{i}^{*}}{\partial Q \partial y_{i}} Q y_{i}+\frac{1}{2} \frac{\partial^{2} \tau_{i}^{*}}{\partial y_{i}^{2}} y_{i}^{2}+\frac{1}{2} \frac{\partial^{2} \tau_{i}^{*}}{\partial Q^{2}} Q^{2}
$$

Thus our full regression equation takes the form:

$$
\tau_{i}^{*}=a x+b y_{i}+c Q+d Q y_{i}+0.5 e y_{i}^{2}+0.5 f Q^{2}
$$

Here, we measure $\tau_{i}^{*}$ by $R_{i}$, an individual's continuous (categorical) stated preference for redistribution, just as we did in specification (4) in Table 2. Estimating equation (A.23) using nonlinear least squares (using HC2 corrected 'robust' standard errors) we confirm the result for our central prediction that $\frac{\partial^{2} \tau_{i}^{*}}{\partial Q \partial y_{i}}>0$. Numerically, the estimated marginal effect is 0.329 with a standard error of 0.077 , while with the 'reduced' model used in the main text we obtained an estimate of 0.379 , with s.e. 0.075 .

\section{Descriptive statistics}


Table A.1: Descriptive statistics

\begin{tabular}{lrrrr}
\hline Continuous variables & Mean & SD & Min & Max \\
\hline Income distance [10.000\$] & 0.076 & 3.595 & -5.687 & 12.542 \\
Inequality (Gini) & 0.557 & 0.053 & 0.439 & 0.697 \\
Inequality (Atkinson) & 0.249 & 0.047 & 0.164 & 0.405 \\
Age [10 yrs] & 3.983 & 1.169 & 2.000 & 6.500 \\
Education [yrs] & 13.338 & 2.866 & 0.000 & 20.000 \\
State unemployment & 6.182 & 2.029 & 2.300 & 17.400 \\
\hline Indicator variables & $\%$ & & & \\
\hline Female & 54.0 & & & \\
Black & 13.5 & & & \\
Other race & 5.4 & & & \\
Part-time employed & 11.9 & & & \\
Unemployed & 6.4 & & & \\
Self-employed & 11.4 & & & \\
\hline
\end{tabular}




\section{Bootstrap standard errors}

Table A.2: Income, inequality and redistribution preferences. Estimates with analytical standard errors in parentheses and cluster-bootstrap standard errors in brackets

\begin{tabular}{lcccc}
\hline & $(1)$ & $(2)$ & $(3)$ & $(4)$ \\
\hline Income & -0.126 & -0.105 & -0.106 & -0.189 \\
& $(0.016)$ & $(0.016)$ & $(0.016)$ & $(0.020)$ \\
Inequality & {$[0.017]$} & {$[0.017]$} & {$[0.016]$} & {$[0.022]$} \\
& 1.402 & 0.696 & 0.994 & 2.195 \\
& $(0.531)$ & $(0.501)$ & $(0.838)$ & $(1.140)$ \\
Incomexinequality & {$[0.628]$} & {$[0.589]$} & {$[0.842]$} & {$[1.091]$} \\
& 0.209 & 0.208 & 0.210 & 0.379 \\
Controls & $(0.058)$ & $(0.058)$ & $(0.059)$ & $(0.075)$ \\
\hline Deviance & {$[0.065]$} & {$[0.063]$} & {$[0.060]$} & {$[0.084]$} \\
BIC & no & yes & yes & yes \\
$\mathrm{N}$ & 22172 & 21718 & 21640 & - \\
\hline
\end{tabular}

Specifications: (1), (2): Random effects, maximum likelihood estimates, (3) Fixed effects, maximum likelihood estimates, (4) Fixed effects, linear probability model. Bootstrap standard errors based on 200 re-samples within state panels. 